\title{
PRUEBA DIRECTA VS. PRUEBA INDIRECTA (UN CONFLICTO INEXISTENTE) *
}

\author{
Carlos de Miranda Vázquez** \\ Universidad Internacional de Cataluña (UIC)
}

RESUMEN. El presente estudio aborda la controvertida cuestión de las relaciones entre prueba directa e indirecta. Más concretamente, se adentra en el análisis de la tradicional superioridad de la prueba directa y en el examen de los fundamentos de la doctrina de la «hipovaluación» de la prueba indirecta.

En una primera parte, el trabajo se centra en la revisión crítica de la aludida doctrina. Seguidamente, se introduce la doctrina de la «equiparación» entre prueba directa y prueba indirecta. El estudio concluye con una toma de postura en relación con los dos cuerpos de doctrina presentados.

Palabras clave: Juicio de hecho, prueba, métodos de prueba, prueba directa, prueba indirecta, prueba indiciaria, presunciones de hombre, «hipovaluación» de la prueba indirecta, «praesumptiopraesumptionis non admittitur».

\section{Direct Evidence vs. Circumstantial Evidence (An Unreal Conflict)}

ABSTRACT. This study broaches the controversial question about the relationships between direct and circumstantial evidence. Specifically, it goes into the analysis of the traditional superiority of the direct evidence and it examines the foundations of the hipovaluation of the circumstantial evidence's doctrine.

In the first part, the study focuses on the critical review of the before mentioned doctrine. Next, it introduces the «equality» between direct and circumstantial evidence's doctrine. The study finishes taking the author a stand in relation to the two described bodies of doctrine.

Keywords: Factual judgment, evidence, methods of proof, direct evidence, circumstantial evidence, presumptions, «underestimation» of the circumstantial evidence, «praesumptiopraesumptionis non admittitur».

* Fecha de recepción: 21 de mayo de 2014. Fecha de aceptación: 30 de junio de 2014.

La idea original de este trabajo vio la luz con ocasión de impartir una sesión, el 15 de mayo de 2013, en el Seminario de Investigación en Derecho Procesal de Baker \&McKenzie (Barcelona) — dirigido por el Prof. PICó I JUNOY-, bajo el título «Prueba directa vs. prueba indirecta en el proceso penal: un conflicto inexistente».

$* *$ Quiero agradecer expresamente las atinadas observaciones de los profesores doctores TARUFFO, PICÓ I JunOY, MuÑoz SABATÉ y ANDINO LÓPEZ, que, sin duda alguna, han contribuido significativamente a mejorar la versión inicial de este trabajo. 


\section{INTRODUCCIÓN}

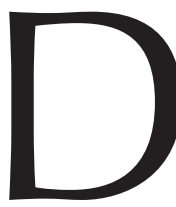

esde antiguo, las pruebas directa e indirecta rivalizan por alzarse con la primogenitura del reino de los métodos probatorios ${ }^{1}$. Y también desde antaño, la prueba directa ha salido mejor parada del enfrentamiento que la indirecta, a la que tradicionalmente se ha mirado con recelo, relegándola sin rubor a un mero papel de suplente de la primera ${ }^{2}$.

Hasta no hace mucho - y a juzgar por la jurisprudencia mayor y menor-, la situación descrita permanecía invariada ${ }^{3}$.

Por lo general, es tal la desconfianza que suscita la prueba indirecta -léase, indiciaria- que, entre otras cosas, no se la permite entrar en escena si se dispone de prueba directa, o no se la admite como elemento probatorio de los propios indicios ${ }^{4}$. Y por si todo esto fuera poco, tanto el Tribunal Constitucional, como el Tribunal Supremo, la han sometido a un asfixiante régimen de requisitos y exigencias que no se contemplan con igual — ni con parecido - rigor para la prueba directa 5 . En definitiva, continúa confinada en un segundo plano, claramente por debajo de la prueba directa ${ }^{6}$. Hasta tal punto ha sido delicada la situación de la prueba indiciaria en nuestro sistema jurídico procesal que su pervivencia, en el ámbito penal, por ejemplo, sólo se explica por una razón de estricta necesidad: sin este método probatorio muchos delitos quedarían impunes ${ }^{7}$. Si la prueba directa pudiera llegar hasta esos recovecos — que hoy le resultan inexpugnables-, téngase por seguro que la prueba indiciaria formaría parte de la colección de reliquias de nuestra cultura jurídica.

Aunque no existe un corpus de doctrina, bien definido y sistematizado, a nadie se le oculta que la opinio iuris a la que me vengo refiriendo existe y no precisamente como un divertimento intelectual de salón, sino como una realidad palpable en nuestra praxis forense y en ciertos sectores de la doctrina jurídica. De ahí que se haya acuñado

1 Sobre el particular, y por extenso, vid. RosonI, 1995.

2 Cfr. IgaRTUa, 2009a: 482.

3 Cfr. Miranda, 1997: 218-221. Desde la perspectiva jurisprudencial, he decidido fijar la atención sobre la STSJ de Castilla-La Mancha, Sala de lo Civil y Penal, núm. 4/2012, de 8 de marzo de 2012, núm. rec. $2 / 2012$ (La Ley 27743/2012). Y ello por dos razones. Primera, porque es reciente. Y, segunda, porque recoge fielmente la doctrina emanada tanto del Tribunal Constitucional, como del Tribunal Supremo, de los últimos veinticinco años.

4 Reservamos el aparato crítico para un momento posterior de la exposición, donde se abordará en profundidad el conjunto de consecuencias que ha comportado la aludida actitud recelosa hacia la prueba indirecta.

5 Me remito a la magistral exposición del fenómeno de M. GASCón, 2010a: 98.

6 De la sentencia antes citada, me permito extractar lo siguiente de su Fundamento Jurídico 2. ${ }^{\circ}$, porque entiendo que resume bien a las claras lo que se ha afirmado en el texto principal. Comienza diciendo que «[...] como es obvio, son muchos los casos en que no hay prueba directa sobre un determinado hecho, y ello obliga a acudir a la indirecta $[\ldots]$... En cuanto a la exigencia de motivación, asevera que es «[...] especialmente exigible cuando se trata de esa clase de pruebas indirectas, a diferencia de los supuestos en los que el fundamento de convicción del Tribunal se sustenta en pruebas directas, en las que es suficiente la indicación de éstas sin que sea preciso, en principio, un especial razonamiento, como por el contrario, es necesario cuando [de] pruebas indiciarias se trata».

7 Por todos, cfr. JimÉnEZ, 1949: 430. Asimismo, la sentencia, de constante cita, lo dice abiertamente en su Fundamento Jurídico 2. ${ }^{\circ}$ De hecho comienza su discurso sobre la aptitud de la prueba indiciaria para enervar la presunción de inocencia fundándola en «[...] la necesidad de evitar la impunidad de múltiples delitos, particularmente los cometidos con especial astucia [...]». 
para esta concepción, a mi modo de ver acertadamente, la denominación de doctrina de la «hipovaluación» de la prueba indiciaria ${ }^{8}$.

La doctrina de la hipovaluación de la prueba indiciaria (en lo sucesivo, más sencillamente DHPI) es algo más — como ya se ha apuntado — que un ejercicio de especulación teórica9 . Tiene muchas y muy graves consecuencias en el ámbito del juicio de hecho. Algunas de ellas revisten relevancia constitucional, toda vez que las principales extensiones de esta doctrina comportan groseras vulneraciones de las garantías constitucionales del proceso, lo que no es cosa de tomarse a la ligera.

No se puede decir que la DHPI no haya encontrado rival alguno y que sea saludada con agrado de forma unánime por la doctrina procesal. Al contrario. Cobra fuerza por momentos una postura teórica que aboga por la completa equiparación entre la prueba directa e indirecta, a todos los efectos ${ }^{10}$. Bien es verdad que este movimiento de resistencia a la imperante DHPI no ha encontrado aún una respuesta clara, decidida y mayoritaria, en el ámbito jurisdiccional, pero quizás sea cosa de tiempo y de que arraigue la semilla sembrada ${ }^{11}$. En cualquier caso, esta postura conceptual tampoco conforma un cuerpo de doctrina sistemático y bien cerrado, pero, a los efectos de este trabajo, no veo impedimento para asignarle el título de doctrina de la equiparación de las pruebas directa e indirecta (en adelante, más sencillamente, DEPPDI).

A mi modo de ver, la pugna entre ambos métodos de prueba debe darse por finiquitada. Y ello por varias razones que, en este momento, me limito a apuntar. La primera y principal es que, como se justificará seguidamente, no existe realmente un conflicto, ni hay lugar para pretendidas rivalidades. Muy al contrario, se da un fenómeno de interdependencia entre ambos métodos, que debería bastar para borrar cualquier pretendido enfrentamiento. La segunda razón estriba en que las sombras que se han cernido secularmente sobre la prueba indiciaria se disipan a poco que se arroje luz sobre este vehículo probatorio. La tercera y última razón —entre otras más que podrían citarse-, de orden estrictamente pragmático, radica en la conveniencia de sumar - frente al desatino de restar - instrumentos de los que pueda valerse el justiciable para probar, si éstos se demuestran válidos desde un punto de vista epistemológico. Cuantos más sean los caminos que conducen a la probanza de los hechos - repito, si dichos caminos son aceptables-, más efectivo será el derecho a la prueba de los justiciables y más garantista acabará resultando nuestro proceso.

El propósito de este trabajo es modesto. No se aspira, desde luego, a agotar la cuestión y a clausurar el debate. Vaya eso por delante. Lo que se pretende más exacta-

8 El primero en emplear la expresión fue MuÑOZ, 1967: 92-100. También se refiere a este fenómeno, empleando el término aludido, SERRA, 1969: 701. Posteriormente, MUÑOZ se ha erigido como la principal voz crítica, tal y como se aprecia en su obra Fundamentos de Prueba Judicial Civil: LEC 1/2000, 2001: 403.

9 Cfr. MuÑoz, 2001: 403.

10 Entre los autores que se alinean con esta doctrina, se cuentan, entre otros, MuÑOZ, SERRA —ambos en citas inmediatamente anteriores-, J. J. GONZÁLEZ, 1975: 390-391; SANGUINETTI, 1979: 98; DÍAZ-REGAÑón, 1996: 39; MirandA, 1997: 225, y el mismo autor en 2000: 498; GimÉnEZ, 2006: 83; y SEOANE, 2007: 352-353.

11 En esta línea, cfr. SSTS (Sala de lo Penal), núm. 33/2005, de 19 de enero, FJ 2. ${ }^{\circ}$ (RJ 2005/944); núm. 192/2006, de 1 de febrero, FJ 5. ${ }^{\circ}$ (RJ 2006/1042), núm. 1175/2011, de 10 de noviembre, FJ 3. ${ }^{\circ}$ (RJ 2012/594). Conviene advertir que la ponencia de las tres resoluciones citadas corrió a cargo del magistrado GIMÉNEZ GARCÍA, quien, como ya hemos anotado oportunamente, se ha manifestado, por escrito y de forma indubitada, a favor de la doctrina de la equiparación. 
mente es, en primer lugar, exponer los principales trazos de la DHPI y someterla a un detenido análisis crítico. Seguidamente, se presentarán los aspectos más sobresalientes de la DEPPDI, concluyendo esta primera parte del trabajo con una toma de postura.

\section{ALGUNAS PRECISIONES TERMINOLÓGICAS Y CONCEPTUALES PREVIAS}

\subsection{A modo de introducción}

Son tres las precisiones que interesa efectuar con carácter previo. Una de ellas atiende a las expresiones «prueba directa-prueba indirecta». Se convendrá con nosotros en que de este binomio cabe efectuar — y de hecho se han efectuado- varias y muy diversas lecturas. Por ello se estima apropiado dejar sentado desde un principio cuál es el sentido que se atribuirá a esos términos en el desarrollo del presente trabajo.

La segunda precisión tiene por objeto revisar — muy someramente- cuál es el mecanismo lógico que encierra el funcionamiento de las pruebas directa e indirecta. La correcta intelección de este aspecto propiciará, a buen seguro, una lectura del texto mucho más provechosa.

Por último - y en tercer lugar-, resulta obligado reseñar la larga lista de expresiones sinónimas que, a lo largo del tiempo, se han atribuido al término «prueba indirecta».

\subsection{Sobre el binomio «prueba directa-prueba indirecta»}

Una primera lectura ${ }^{12}$ que se puede hacer de ambos términos — tan válida como las que se expondrán seguidamente, dicho sea de paso- es la que resulta de prestar atención a la relación que se establece entre el juzgador y la realidad que está detrás del factumprobandum. Así, se considera prueba directa a aquella en la que el juzgador entra en contacto personal y directo con dicha realidad de contraste. Mientras que en el caso de la prueba indirecta no se produce tal contacto personal y directo, sino que alguien - una persona - o una cosa — un instrumento o un hecho- se interponen entre el juzgador y el factumprobandum. En los términos planteados, sólo constituye auténtica prueba directa el reconocimiento judicial. Y, más exactamente, en el proceso penal, se trataría de la inspección ocular del hecho delictivo por parte del órgano enjuiciador, lo cual es de todo punto infrecuente. En cambio, recibirán el calificativo de indirectos el resto de métodos de prueba (personal, documental, audiovisual, e indiciario). Debe apostillarse, ya desde este momento, que no es éste el sentido que se conferirá al binomio «prueba directa-prueba indirecta» en este trabajo.

12 El principal valedor de este enfoque es CARNELUTTI, tal y como explica con gran detalle LOMBARDO, 1999: 319. Para el maestro italiano, toda la prueba se reduce a «percepción y deducción». En este mismo sentido, entre otros, $c f r$ PAGANO, 2002: 97-98; D. GonZÁLeZ, 2003: 41; GimÉNEZ, 2006: 77; M. GASCón, 2010a: 79 . 
Una segunda lectura ${ }^{13}$ distingue según la prueba tenga por objeto un hecho que forme parte del supuesto fáctico de la norma jurídica implicada o, por el contrario, un hecho de los denominados secundarios. En el primer caso, se nos dirá que se trata de prueba directa. En el segundo, se reputará prueba indirecta. Este planteamiento comporta que un método de prueba - a excepción, como enseguida se verá, de la prueba indiciaria - pueda jugar un papel de prueba directa en unas ocasiones y de prueba indirecta en otras ${ }^{14}$.

Tomemos por caso la prueba testifical. Un mismo testigo - Sempronio-, puede reputarse en unos supuestos prueba directa y, en otros, prueba indirecta. Veámoslo con un sencillo ejemplo. Si Sempronio presencia cómo Cayo apuñala a Ticio, hasta que éste cae muerto a sus pies, se calificará el testimonio de Sempronio como prueba directa. El elemento clave del supuesto de hecho del delito de homicidio es, precisamente, dar muerte a alguien. Y eso es exactamente lo que presenció Sempronio. En cambio, si lo que vio nuestro testigo fue que Cayo salía de la vivienda de Ticio, por una ventana, con un cuchillo en la mano, y las ropas ensangrentadas, su testimonio recibirá la consideración de indirecto. Todo lo que nos refiere Sempronio, en este último caso, son hechos secundarios que, a su tiempo, podrían permitir construir una inferencia presuntiva hasta alcanzar finalmente la conclusión de que Cayo mató a Ticio ${ }^{15}$.

No obstante constituir este planteamiento un legítimo enfoque de la cuestión, ya anticipo que tampoco será ésta la perspectiva de la dicotomía «prueba directa-prueba indirecta» que se asuma en este estudio.

Una tercera manera de ver el binomio objeto de estudio ${ }^{16}$ pasa por distinguir la relación que guardan la información que recibe el juzgador sobre la realidad con ésta última. Me explico mejor. En el caso de la prueba directa, se dirá que esta última «representa» la realidad. Ya sea una fotografía, una proyección audiovisual o la narración de un testigo, en todos estos casos se traslada al juzgador una proyección, más o menos homogénea, de la realidad. En cambio, en la prueba indirecta la información que se proporciona al órgano jurisdiccional no guarda el menor parecido con la realidad, $\mathrm{y}$, sin embargo, permite establecer un vínculo racional asociativo. A ambas clases de prueba se las ha denominado, respectivamente, representativa y crítica ${ }^{17}$.

Volvamos a echar mano del ejemplo anterior. Cuando Sempronio relata cómo presenció el apuñalamiento de Ticio o la extraña conducta de Cayo (saliendo por la ventana, cuchillo en mano, y ensangrentado), su narración representa la — pretendida— realidad, en la medida en que la describe. El discurso es una imagen de lo sucedido. En cambio, y con respecto al factumprobandum «Cayo apuñaló a Ticio», los hechos narrados por Sempronio relativos a la forma en que Cayo salió de la vivienda de Ticio, a que portara un cuchillo en

13 En este sentido, confróntense FramarinO, 1896: 185-186; IACOVIELlO, 1997: 158; LOMBARDO, 1999: 316; IGARTUA, 2009b: 643.

14 Cfr. IACOVIELlo, 1997: 158 y M. Gascón, 2010a: 81.

15 No se nos escapa que esta forma de enfocar la dicotomía «prueba directa-prueba indirecta» presenta algunos flancos débiles. Baste fijarse en uno. Aunque Sempronio presenciase la escena del apuñalamiento, resulta arriesgado inferir de sus palabras que Cayo causara la muerte de Ticio. Lo que no admite dudas del testimonio es que el acusado apuñaló varias veces a su víctima. Lo que puede ser discutible, por el contrario, es que Cayo falleciera a causa de esas lesiones, porque, quizás, acabara con su vida un infarto que sufriera al inicio mismo del acometimiento. Esta observación es deudora del pensamiento de BuRRILL, 1868: 210-211; FRAMARINO, 1896: 185; y ELLERO, 1994: 91.

16 Cfr. Tonini, 2003: 187-188; Santoriello, 2008: 340; TARuffo, 2008: 60; S. E. Rodríguez, $2013: 303$.

17 Para un análisis extenso y detallado del pensamiento carneluttiano, vid. LOMBARDO, 1999: 322. 
la mano y a que estuviese su ropa ensangrentada, no guardan, por supuesto, identidad, pero tampoco semejanza. Lo uno no es imagen de lo otro. Sin embargo, es posible transitar racionalmente de estos hechos hasta alcanzar la conclusión «Cayo apuñaló a Ticio».

La perspectiva expuesta es justamente la que se adoptará en este trabajo y será este entendimiento de las pruebas directa e indirecta el que se manejará en todo momento. No es ni mejor, ni peor, que los anteriores. Sencillamente, se trata de otro enfoque, más sencillo, a mi entender, porque permite prescindir de la calificación del enunciado a probar como principal o como secundario (este enfoque es válido para cualquier factumprobandum). A la par, considero que se ajusta más a la concepción que tienen en general los operadores forenses cuando se les menciona la dicotomía que nos ocupa.

\subsection{Sucinta alusión al concepto de «prueba» y a los principales métodos probatorios}

Es lugar común que su necesidad — la de recurrir a la prueba- resulta de la existencia de una proposición fáctica controvertida. Y lo que precisa el juzgador en esa situación es contar con razones que justifiquen poder asumir — hacer suya- esa proposición ${ }^{18}$. Esas razones no son otra cosa que información sobre la realidad, que se le provee por las fuentes de prueba a través de los medios probatorios ${ }^{19}$.

Esa información la puede obtener el juzgador a partir de la contemplación, directa y personal, de la realidad que, a priori, se corresponde con la proposición fáctica disputada. Este método permite al juzgador extraer por sí mismo un enunciado descriptivo de la realidad. Posteriormente, bastará con que enfrente ambas proposiciones fácticas — la controvertida y la empírica - y concluya si cabe establecer identidad — sustancial- entre ambas ${ }^{20}$. En caso afirmativo, el factumprobandum se reputará probado.

Por otra parte, la información puede provenir de personas o de instrumentos en los que — se dice- se ha «estampado» el reflejo de la realidad ${ }^{21}$. Como hemos señalado antes, estas fuentes — «recipientes»— de información, «representan» — supuestamente- la realidad ${ }^{22}$. También aquí el juzgador procederá a enfrentar ambos enunciados — la afirmación discutida y la afirmación o la reproducción instrumental — y determinará si existe, o no, identidad -insisto, sustancial ${ }^{23}$. De haberla, el factumprobandum se tendrá por probado.

Por último, la información — que podrá provenir, desde luego, de cualquiera de las dos anteriores vías-, puede resultar ajena por completo a la proposición fáctica con-

18 Para un estudio extenso y detallado de la cuestión, vid. FERRER, 2006: 1-45.

19 En un sentido similar, SANTORIELLO, 2008: 39.

20 En cuanto a la coincidencia lógico-semántica de las dos proposiciones fácticas enfrentadas, cfr. BELLOCH, 1992: 43; LOMBARDO, 1999: 430; FERRUA, 2007: 71 —quien habla de correspondencia entre entidades lingüísticas-; SANTORIELLO, 2008: 348. Sobre el carácter tautológico del razonamiento identificativo, $c f r$. LOMBARDO, 1999: 467 y 475-476 — quien alude a una inferencia formal sustentada sobre el principio lógico de identidad-, e IGARTUA, 2009b: 644-645 — que predica una relación de identidad existente, en el plano lógicosemántico, entre las dos proposiciones, factumprobandum y factumprobans-.

21 Expresión original de MuÑOZ, 2007: 54-55.

22 Claramente, UBERTIS, 1995: 41.

23 Cfr. Climent, 2005: 861. 
trovertida ${ }^{24}$. Sin embargo, da pie a que el juzgador establezca una asociación de datos sobre la base de una asociación general de ideas, a modo de ley, regla o patrón, que se conoce técnicamente como máxima de experiencia. Si es dable establecer esa relación lógica, podrá considerarse probado el aserto factual discutido ${ }^{25}$.

Los dos primeros métodos probatorios - perceptivo y representativo- los he dado en englobar dentro del término «prueba directa». El tercero de ellos —crítico o lógico-, y que se le conoce bajo un buen número de apelativos (presunciones, prueba indiciaria, prueba circunstancial, etc.), lo he situado, en solitario, bajo el paraguas del concepto «prueba indirecta».

\subsection{La diversa nomenclatura para aludir a la prueba indirecta}

Son muchísimos los apelativos que ha recibido a lo largo del tiempo (presunciones, prueba de presunciones, presunciones de hecho, presunciones de hombre, prueba indiciaria, prueba de indicios, prueba por indicios, prueba circunstancial, prueba conjetural, prueba crítica, prueba lógica, prueba de inducción, prueba de deducción, inferencias indiciarias, prueba artificial, cálculo presuncional... ${ }^{26}$, pero todos significan lo mismo, o mejor, refieren lo mismo: prueba indirecta.

De todas cuantas acepciones se han consignado, sólo dos merecen ahora nuestra atención. Tradicionalmente, se ha empleado la expresión presunción (o presunción judicial) en el ámbito del derecho privado, mientras que en la praxis penal se alude mayoritariamente a la prueba indiciaria. Pues bien, conviene subrayar que se trata de términos sinónimos, sin que la diferencia nominal provenga de distinción conceptual alguna [por todas, STS de 15 de octubre de 1990, FJ 2. ${ }^{\circ}$ (La Ley 513/1991)] 27. Por tanto, y en lo sucesivo, se utilizarán ambas expresiones de forma indistinta y, siempre, como expresiones sustancialmente equivalentes a prueba indirecta.

\section{ANÁLISIS DE LAS DOCTRINAS EN LIZA. TOMA DE POSTURA}

\subsection{Exposición de la DHPI}

El leitmotiv de esta doctrina puede enunciarse de manera sencilla: la prueba directa es (netamente) superior a la prueba indirecta ${ }^{28}$. Tal superioridad se predica en relación con su fuerza de convicción ${ }^{29}$. Y la mayor valencia probatoria de la prueba directa obedece a la superior confianza que inspira, frente a la prueba indirecta de la que se debe recelar ${ }^{30}$.

\footnotetext{
24 Por todos, cfr. Lombardo, 1999: 488.

25 Sobre el razonamiento presuntivo, por extenso, DE MiRANDA, 2014.

26 Lista tomada de LEGUISAMÓN, 2006: 42-43.

27 Cfr. MARTíneZ, 1993: 55.

8 Cfr. Framarino, 1896: 193.

9 Cfr. TOMÁs y VALIENTE, 1987: 31, y M. GASCÓN, 2010a: 98-99.

30 Cfr. Miranda, 1997: 218-221, y del mismo autor 2000: 498.
} 
La razón fundamental que sustenta dicha discriminación estriba en la consideración de que la prueba directa se presenta de modo inmediato a la razón, sin que medie reflexión alguna ${ }^{31}$. Y he aquí el quid de la cuestión. Si no median inferencias, queda conjurado de plano el riesgo de incurrir en errores lógicos. Por el contrario, la prueba indirecta es estrictamente racional — de ahí el apelativo «crítica»—y, por ende, abocada a un inevitable riesgo de yerro ${ }^{32}$.

De ahí que se afirme que la prueba directa es más simple —más sencilla— desde una perspectiva intelectiva o lógica [STC, Sala 1. ${ }^{a}$, núm. 174/1985, de 17 de diciembre, FJ 3. ${ }^{\circ}$ (La Ley 520-TC/1986) ] ${ }^{33}$. También se entiende que se aduzca que, a la par, es menos peligrosa, por cuanto entraña menor riesgo de error ${ }^{34}$. La prueba directa va derecha al hecho y resulta inmediatamente de los medios de prueba. En cambio, la prueba indirecta da un rodeo lógico que obliga a concatenar inferencias, alimentándose con ello un perturbador espacio para el equívoco [SSTC, Sala 2. ${ }^{\text {, }}$, núm. 169/1986, de 22 de diciembre, FJ 1. ${ }^{\circ}$ (La Ley 83787-NS/0000) y Sala 2. ${ }^{a}$, núm. 256/1988, de 21 de diciembre, FJ 2. ${ }^{\circ}$ (La Ley 2655/1988)].

Asimismo, se ha formulado otra razón para la subsidiariedad. Como ha defendido PASTOR AlCOY, «[...] puede ser más fácil para la defensa combatir un falso testigo que falsos indicios» ${ }^{35}$.

Por último, se ha sostenido que el empleo de la prueba indiciaria en el ámbito penal — por parte de la acusación- (cuando los indicios sean remotos o débiles) comporta una suerte de inversión de la carga de la prueba, ya que el «[...] acusado [...] se vería compelido de esta forma a demostrar que la presunción o inferencia más común, sin embargo, no es la real. [...]. Lo grave de esta situación es que dadas las circunstancias en que han ocurrido los hechos enjuiciados — ausencia de testigosla prueba de descargo para contrarrestar los indicios resulta ser, en muchos casos, imposible» ${ }^{36}$.

Esta superioridad comporta, entre otras cosas, que, si se cuenta con prueba directa, debe desecharse automáticamente cualquier prueba indirecta y los razonamientos probatorios que de ésta puedan derivarse ${ }^{37}$.

Asimismo, únicamente se podrá echar mano de prueba indirecta cuando no haya sido posible practicar ninguna prueba directa o ésta no haya dado un resultado satisfactorio $^{38}$.

31 ONECHA, 1971: 953, afirma que «[...] la prueba incorpora los medios de conocimiento que inmediatamente van a permitir formar juicio [...]». Asimismo, JimÉNEZ, 1949: 417. Para una descripción detallada de esta pretendida exención de razonamiento en la prueba directa, M. GASCÓN, 2010a: 98.

32 Cfr. BRICHETTI, 1973: 127-130.

33 PRIETO-Castro y GutiéRREZ DE CABIEDES, 1982: 252, subrayan el «[...] esfuerzo lógico-jurídico intelectual necesario $[\ldots] \gg$ al acometer la prueba indirecta.

34 Ibid., 1982: 253, llegan a calificar la prueba indirecta como muy peligrosa.

35 PASTOR, 2003: 168.

36 Ibid., 167.

37 Cfr. LEONE, 1963: 167, y CABAÑAS, 1992: 287, quien, incluso, afirma que «[...] existiendo en autos un medio probatorio de ésta última especie (que suministre un dato fáctico fiable en una cierta dirección), el mismo no puede ser rebatido (a fin de cuentas, canjeado) por el resultado de prueba que se obtenga de presunción». En parecido sentido, A. DíAZ, 2002: 372.

38 Cfr. Garberí, 2004: 521, y Climent, 2005: 870. 
La desconfianza hacia la prueba indirecta es de tal magnitud que algunos autores han llegado a postular que quien quiera valerse de ella tendrá que acreditar, inexcusablemente, la indisposición de prueba directa ${ }^{39}$. Conviene aclarar que los defensores de esta exigencia probatoria se han limitado a formular tal aserto, sin que, al tiempo, hayan efectuado precisión alguna — hasta donde se me alcanza- a este respecto.

En consonancia con lo dicho hasta aquí, debe darse por descontado que disponiendo de ambos métodos probatorios en un mismo asunto, el justiciable sólo podrá valerse de prueba directa, sin que quepa articular su estrategia probática valiéndose de ambos métodos probatorios al alimón.

Otra aplicación concreta de esta doctrina es la conocida máxima «praesumptiopraesumptionis non admittitur». Según este brocardo, los indicios no se podrán probar en ningún caso por medio de prueba indirecta. Sólo cabrá sustentar los hechos-indicio sobre pruebas directas ${ }^{40}$ [por todas, SSTS, Sala 2. ${ }^{a}$, de 14 de octubre de 1986, FJ 2. ${ }^{\circ}$ (La Ley 11404-JF/0000), de 7 de abril de 1989, FJ 2. (La Ley 1338-2/1989), y de 15 de octubre de 1990, FJ 2. (La Ley 513/1991)].

La DHPI trae consigo, por otra parte, la necesidad de redoblar la exigencia de motivación judicial en el caso de la prueba indiciaria ${ }^{41}$, imponiéndose una serie de severos criterios - algunos de una inconcreción alarmante- a la hora de proceder a su plasmación en la fundamentación jurídica de las sentencias [STC, Sala 2. ${ }^{a}$, núm. 150/1987, de 1 de octubre, FJ 2. ( (La Ley 885-TC/1988)]. Todo lo contrario acontece con la prueba directa a la que prácticamente se exime de cualquier exigencia de motivación [STS, Sala 2..$^{a}$, de 25 de abril de 1996, FJ 2. (La Ley 4896/1996)] ${ }^{42}$. Al albur de la —-mal entendida - inmediación judicial, se aplica a los medios de prueba - especialmente, a los personales, los documentales y los audiovisualesuna suerte de rebaja de la exigencia en lo tocante al deber judicial de motivación (ex art. $120.3 \mathrm{CE})^{43}$.

Por todo lo dicho, cabría esperar que los valedores de esta doctrina propugnaran la definitiva erradicación de la prueba indirecta de nuestro sistema jurídico procesal. Sería lo más apropiado, visto cuanto se ha expuesto. Sin embargo, y de forma sorprendente, esta doctrina acepta la prueba indirecta como un mal menor, bien que únicamente en aquellas concretas situaciones en las que se carezca de prueba directa. Su empleo como solución de fortuna obedece a la constatación de que su rechazo total y absoluto impediría la prueba de muchos supuestos fácticos (para los que se carece de prueba directa o revisten la condición de hechos psíquicos) [STC, Sala 1. ${ }^{a}$, núm. 174/1985, de 17 de diciembre, FJ 3. (La Ley 520-TC/1986)]. Amén de que,

39 Así, claramente, RIFÁ, 2000: 1783, y PASTOR, 2003: 168. En ambos casos, queda abierto un importante interrogante: ¿Qué se tiene que probar exactamente? ¿Que no hay prueba directa o que no se ha podido disponer de la misma?

${ }^{40}$ Cfr. A. DíAz, 2002: 374-375, quien sustenta su postura en una interpretación literal del art. 386 LEC, según la cual el empleo de la expresión prueba supondría la exclusión consciente — por parte del legisladorde las presunciones como método de prueba de los indicios.

41 Por todos, Tomás y Valiente, 1987: 22.

42 MANZANARES, 1992: 95 y 98-99, advierte que es la propia Ley de Enjuiciamiento Criminal la que guarda silencio al respecto — vid. arts. 147 y $741-$, sin que, por otra parte, ni el Tribunal Constitucional, ni el Tribunal Supremo, hayan cuestionado la constitucionalidad de tal silencio.

43 Abiertamente, M. GASCÓn, 2010a: 98 y 102. Denuncia también esta situación GIMÉNEZ, 2006: 82. 
concretamente en el plano penal, resultaría de todo punto imposible la probanza del tipo subjetivo del delito y de los eventuales elementos subjetivos del tipo.

\subsection{Análisis crítico de la DHPI}

La doctrina de la «hipovaluación» no resiste un detenido análisis crítico. Y al efecto de demostrar tal aseveración, vamos a mostrar, a continuación, sus principales debilidades. Para ello se ofrecerá una serie de argumentos, que atienden a distintos aspectos de la prueba, como son el puramente legal, el epistemológico, el lógico y el histórico.

\subsubsection{Argumentos jurídicos}

i) Para empezar, la DHPI carece por completo de apoyatura legal que le confiera la menor legitimación ${ }^{44}$. Ninguna norma procesal contempla, en precepto alguno, que la prueba indiciaria revista menor valencia probatoria que la prueba directa. Tampoco se establece que el justiciable únicamente pueda valerse de prueba indirecta a falta de prueba directa, a modo de solución supletoria [STC, Sala 1. ${ }^{a}$, núm. 263/2005, de 24 de octubre, núm. rec. 5134/2002, FJ 5. ${ }^{\circ}$ (La Ley 10067/2006)] ${ }^{45}$.

ii) Por otra parte, la discriminación que supone la doctrina objeto de análisis contraviene frontalmente el principio de legalidad (procesal). Ubilex non distinguit, nec nos distinguiredebemus ${ }^{46}$. Por consiguiente, donde el legislador no ha fijado semejante tarifa probatoria, ni ha contemplado pruebas de distinto grado, no pueden los juzgadores introducir alteraciones en el orden probatorio establecido. No puede perderse de vista que los órganos jurisdiccionales están sometidos al imperio de la ley — art. 6 Ley Orgánica del Poder Judicial (LOPJ)_, sin que quepa admitir fisuras de ninguna clase. Otra cosa abre las puertas de par en par a la inseguridad jurídica y, en última instancia, a la arbitrariedad.

iii) En consonancia con lo anterior, no es de recibo que se pueda llegar a exigir la acreditación de la indisposición de prueba directa para poder hacer valer prueba indirecta. La probanza de un hecho negativo de estas características constituye una auténtica probatiodiabolica ${ }^{47}$, en toda la extensión del término ${ }^{48}$. Y ningún precepto

44 Cfr. Chocrón, 2004: 32, y Giménez, 2006: 83. Por su parte, RuIz, 1995: 267, defiende que el libre convencimiento del juzgador es incompatible con la existencia de tasa de prueba alguna, cosa que también sostiene FUENTES, 2000: 167. RODRÍGUEZ, 2012, afirma que «[...] el artículo 741 LECrim le atribuye (al Tribunal) una omnímoda y soberana facultad valorativa de las pruebas practicadas, en las que no se admite jerarquía ni preeminencia de unos medios probatorios sobre otros $[\ldots] \gg$.

45 Otorgar mayores y menores valores probatorios, esto es, jerarquizar los métodos de prueba, supone retroceder a planteamientos propios de la Edad Media, donde reinaba la prueba legal o tasada, lo que, por supuesto, acabaría con el principio del libre convencimiento judicial. Así, cfr. AsENCIO, 1989: 61, e IGARTUA, 2009a: 482-483. Vid., si no, a dónde se puede llegar, tal y como señala CABAÑAS, 1992: 288: «[...] En el sentido de perder éste [el juez] su libertad inicial para fallar de manera opuesta, intentando justificar la mayor validez de la prueba crítica».

46 Sobre el brocardo, sus diversas formulaciones y su significación, vid. VVAA, 2006: marginal 902.

47 Acerca de este concepto, vid. MuÑOZ, 2012: 23-24.

48 Curiosamente, PASTOR, 2003: 168 — defensor de la exigencia de probar la inexistencia de prueba directa para poder valerse de la indirecta - afirma que «no se puede exigir a ninguna parte pruebas imposibles o diabólicas». 
legal ampara tal cosa, a tenor del ordenamiento jurídico vigente. Es más, tan excesiva exigencia no sólo no encuentra cobijo en ningún precepto de nuestras leyes procesales, sino quesembrar de obstáculos el camino del litigante para valerse de un método de prueba legítimo supone atentar abiertamente contra el derecho fundamental a la prueba [art. 24.2 Constitución Española (CE)]. En última instancia, la imposición de tal requisito comporta la desactivación de facto de la prueba indiciaria. La extrema dificultad de probar la indisposición de prueba directa convierte en ilusoria cualquier expectativa del justiciable de servirse de presunciones. Y mucho me temo, además, que sólo se permitiría el acometimiento de esa difícil — por no decir imposible— probanza mediante prueba directa.

iv) Descendiendo al terreno del proceso penal, el empleo de presunciones por parte de la acusación (por débiles o remotos que sean los indicios) no comporta ninguna suerte de alteración, inversión o traslación de la carga de la prueba hacia el acusado, como ha afirmado algún autor ${ }^{49}$. Si los indicios son remotos o débiles y, por tanto, la inferencia es excesivamente abierta, no se produce un supuesto de traslado de la carga probatoria, sino que lo procedente, en tal caso, es «infirmar» ${ }^{50}$ generando en el juzgador una duda razonable. Baste un sencillo ejemplo para ilustrar nuestra objeción. Nos enfrentamos al hurto de una bicicleta y al hecho de que al acusado se la ha sorprendido en posesión de la misma quince días después de producida la sustracción. No me parece que haya lugar a desplazamiento alguno de la carga de la prueba, ni tampoco se me alcanza un fenómeno de inversión del onusprobandi. Sencillamente, lo que procede es que el acusado infirme la hipótesis acusatoria. Bastaría con establecer otras asociaciones lógicamente posibles sobre la misma base indiciaria (hurto de hallazgo, receptación, forma de pago del precio de una deuda, etc.). Luego, si es por eso, no debe preocuparnos lo más mínimo el que la prueba indiciaria se pueda basar en indicios remotos o débiles. Tal circunstancia no perjudica en modo alguno al acusado. Más bien, sucede todo lo contrario.

Tampoco se produce el aludido desplazamiento de la carga probatoria cuando los indicios son falsos. En tal supuesto, será suficiente con que el acusado lo alegue y lo demuestre.

Sea como fuere, no cabe, en mi opinión, sustentar la subsidiariedad de la prueba indirecta en una razón que no es tal, por cuanto no hay lugar para la pretendida inversión del onusprobandi.

\subsubsection{Argumentos epistemológicos}

i) La DHPI se asienta sobre un error conceptual de base, en absoluto baladí, que no es otro que comparar métodos probatorios sustancialmente distintos. Las cosas que son diferentes, entre sí, no admiten comparación ${ }^{51}$. Ya hemos visto en un epígrafe anterior que se trata de dos métodos de prueba por completo disímiles, que operan de forma distinta y que tienen objetos dispares.

49 Cfr. PASTOR, 2003: 167

50 Según MuÑOZ, 2007: 101, debe entenderse por «infirmación» «[...] cualquier otra conclusión oponible a una presunción e inferida del mismo indicio».

51 Cfr. Burrill, 1868: 230; GorpHe, 1955: 461 —quien cita a Wigmore—; y SERRA, 1993: 571. 
ii) Sin perjuicio de que se repute censurable, de por sí, la comparación de lo que es esencialmente diferente, la DHPI lleva a efecto una comparación para la que carece por completo de términos o unidades de medida. Los parámetros necesarios para llevar a buen puerto tal paralelismo sencillamente no existen, puesto que nos estamos refiriendo a realidades —el conocimiento, la convicción — que no son susceptibles de sujetarlas a unidades numéricas de medida. Y no sólo no se dispone de una suerte de relación de criterios tasados, a los que aparejar valores determinados, sino que tampoco se presentan tales criterios de forma jerarquizada. Cabe preguntarse si la prueba directa es superior por su simplicidad o porque reclama la superación de menos pasos lógicos. Y, asimismo, es dable interrogarse por el valor que se asigne a la mayor resistencia de la prueba indiciaria a la manipulación y a la adulteración. Por lo visto, esto último debe contar bien poco a la vista del resultado final que alcanzan los defensores de la DHPI.

iii) Por otra parte, los paladines de la DHPI no aducen razones de orden estrictamente epistemológico en las que cimentar sus conclusiones y en las que basar sus criterios de preferencia. Y no lo hacen porque, sencillamente, resulta imposible ${ }^{52}$. Tan se puede conocer la realidad pasada (extinta) por una vía, como por otra. Ningún autor de los que se alinea con la doctrina objeto de crítica ofrece referencias bibliográficas de epistemólogos que hayan alcanzado semejante conclusión. La jurisprudencia tampoco manifiesta criterio alguno de orden epistémico en el que sustentar su postura.

iv) Desde la perspectiva de las supuestas ventajas de la prueba directa, los resultados tampoco acompañan. En particular, supone un fundamento sumamente endeble pretender una mayor simplicidad «intelectual» o lógica de la prueba directa sobre la prueba indirecta. Se desprende de las palabras de los adalides de esta doctrina la idea de que «al testigo no hay que "pensarlo", hay que escucharlo. Al indicio, no hay que escucharlo, hay que "pensarlo" »53. Sin embargo, la tal supuesta «simplicidad» es un espejismo ${ }^{54}$. Obviamente, exige menos esfuerzo el acto de escuchar y de identificar la información recibida con el themaprobandum, que aventurarse a buscar sesudas asociaciones lógicas entre éste último y los indicios reunidos en la causa. Sin embargo, los defensores de esta doctrinase olvidan de la enjundiosa tarea de analizar críticamente a la fuente de la que procede la información que «basta escuchar» ${ }^{55}$. Este descuido de

52 Cfr. AndRÉs, 2009: 51 e IgARTUA, 2009b: 644. De ahí que los —tímidamente- críticos con la DHPI digan que «esta subestimación no es justificada [...]», como es el caso de DöHRING, 1972: 313, y en sentido semejante, se pronuncian VEGAS, 1993: 138-139 — para quien «[...] no tiene [...] ninguna justificación»—y DELGADO, 1996: 391 — quien afirma que «en principio no hay razón [...]» para la discriminación peyorativa que nos ocupa-.

53 BURRILL, 1868: 224, percibió claramente que en este punto residía la razón última de la afirmada superioridad de la prueba directa sobre la indirecta. ROCHA, 1967: 605-606, tiene dicho que «el testimonio también es prueba directa y sin más razonamiento que el de la sana crítica va demostrando el hecho, del cual además queda una persuasión sensitiva». Por su parte, CABAÑAS, 1992: 287, asevera que «el carácter mediato del vínculo que une al hecho base con el objeto representado para la articulación de la presunción bominis, trae como natural consecuencia la preferencia dentro del sistema procesal, de toda fuente de convicción fundada en un medio de prueba representativo, en menoscabo del mecanismo presuncional».

54 Al respecto, $c f r$. GIANTURCO, 1958: 133; BRICHETTI, 1973: 127; D. GONZÁLEZ, 2003: 44 —quien piensa que afirmar que en prueba directa no interviene ningún razonamiento constituye una falacia-, y del mismo autor, 2010: 321; GIRONI, 2008: 150; SANTORIELLO, 2008: 344; M. GASCÓN, 2010a: 81-82.

55 BENTHAM, 1823: 244, señala que es más sencilla la prueba indirecta que la directa, y se fija precisamente en la enorme dificultad que encierra la valoración del testigo. MuÑOZ, 1967: 205-207, habla de juicio de 
los defensores de la DHPI obedece, en gran medida, a la aceptación acrítica de la concepción que hoy en día impera en relación con el principio de inmediación judicial y la valoración de la prueba directa de carácter personal. Como se defenderá más adelante, por extenso, el «simple» acto de escuchar y de percibir a la persona del testigo -me refiero al lenguaje no verbal - encierra, aunque nos empeñemos en negarlo, un proceso inferencial ${ }^{56}$, de naturaleza presuntiva ${ }^{57}$.

A la vista de datos —indicios-, extraídos muchos de ellos de la forma de expresarse y de comportarse del testigo, se aplican máximas de experiencia — de fundamento y rigor cuestionables-, cuyo desenlace último es un juicio sobre la confiabilidad de dicha fuente de prueba. Quizás se deba a que tenemos estos procesos mentales sumamente interiorizados, pero lo cierto es que suceden sin que nos demos cuenta de ello ${ }^{58} \mathrm{y}$, por ende, sin que seamos realmente capaces de poder expresar o justificar cómo hemos alcanzado las conclusiones ${ }^{59}$.

Es más, me atrevería a sugerir que hay supuestos — no pocos— donde la prueba indirecta es más «simple» que la prueba directa. Cuando la prueba indiciaria se sustenta sobre piezas de convicción, cuya obtención se ha producido de forma regular, y el razonamiento que resulta de ellas es sencillo — por basarse en máximas de experiencia «hipercodificadas»- se me antoja mucho más asequible, desde un punto de vista intelectivo, que el análisis — riguroso — de un testigo, sobre la base de los aún vacilantes fundamentos de la psicología del testimonio ${ }^{60}$.

Bien podría concluir aquí el argumentario crítico de la DHPI. Como he señalado en los primeros compases de la exposición de dicha doctrina, en la raíz de la discriminación entre ambos métodos de prueba está la supuesta inmediatez de la probanza directa, que no precisa de razonamientos, al contrario de lo que sucede, ciertamente,

valoración. LOMBARDO, 1999: 428 y 430, señala acertadamente que al enfrentamiento entre proposiciones para buscar coincidencia en el plano lógico-semántico, lo precede una fase de análisis crítico sobre la fiabilidad de la fuente de información, lo que, por otra parte, ya había vislumbrado GIANTURCO, 1958: 133, y posteriormente se aprecia en FASSONE, 1995: 321; IACOVIELLO, 1997: 168; FERRUA, 2007: 335; y SANTORIELlO, 2008: 39.

56 Cfr. MitTermaier, 1929: 318; GorpHe, 1955: 154; Belloch, 1992: 43; IgARTUA, 1993: 46; y del mismo autor, 1995: 111 — «[...] la "verdad" de un testimonio o la "convicción" de un informe son inaprehensibles sensorialmente [...]»— y 115; M. GASCÓN, 1999: 89-90; CLIMENT, 2005: 86 —aunque se refiera a deducciones con forma silogística一; D. GonZÁlez, 2006: 90; SANTORIELlo, 2008: 346; IgARTUA, 2009b: 645; TARUfFo, 2012: 221.

57 La clave no está tanto en el mensaje, sino en el mensajero. Cfr., en este sentido, FRAMARINO, 1896: 188; GianturCO, 1958: 134; ElLERO, 1994: 66 y 75; M. GASCÓN, 1999: 89-90 — «para quien no hay [...] ninguna distinción esencial [...] pues en ambos casos están presentes inferencias de la misma clase y, en consecuencia, tan "teñida de subjetividad" puede estar la primera como la segunda»—; de la misma autora, 2010: 99.

${ }_{58}$ Cfr. BONNIER, 1869: 354; GORPHE, 1955: 39 —aquí, en testigos, dice, la inferencia pasa inadvertida一; Amodio, 1977: 209 —quien habla de un proceso mental intuitivo—; ANDRÉs, 1992: 262; D. GONZÁLEZ, 2003: 41; RIVERA, 2011: 303.

59 M. GASCÓN, 1999: 45, se refiere al proceso intelectual de valoración de las pruebas como algo «[...] difícilmente explicable con palabras», lo que desemboca en la «motivación implícita» o la «motivación no dicha», a la que alude ANDRÉS, 1992: 289.

${ }^{60}$ Cfr. GoRPHe, 1955: 43; asimismo, y más modernamente, NiEva, 2010: 95, quien ha advertido sobre los riesgos de las máximas de experiencia en relación con su origen y su fiabilidad. De aquí que ANDRÉS, 1992: 292, afirmara que prueba directa no es sinónimo de prueba simple, conclusión a la que llega también D. GoNZÁLEZ, 2010: 321. Según LOMBARDO, 1999: 433, el juicio sobre la fiabilidad de la prueba directa, además de complejo, suele implicar un gran número de inferencias. Es más, en su día, BELLOCH, 1992: 43-44, argumentó de forma convincente que en algunos supuestos, se antoja más simple la prueba indirecta que la directa. 
con la indirecta. Así pues, desactivada esta errada suposición, y habiendo concluido que en ambas interviene el raciocinio, la afirmada sustancial diferencia entre ambas se desvanece automáticamente. Sin embargo, no está de más ahondar en otros argumentos que contribuyen a dar solidez a nuestra crítica de la DHPI.

v) Conviene, ahora, prestar atención al propalado valor de la seguridad, que se predica como claramente superior en la prueba directa. Pues bien, a mi modesto entender, la prueba directa no es más segura — desde una perspectiva material— que la prueba indirecta. Bien mirado, y asumiendo que la prueba directa consiste habitualmente en prueba personal, no se puede aceptar que una prueba directa sea más segura que una prueba indirecta, cuando la primera es susceptible, en mayor medida, de resultar adulterada o sencillamente de quedar desvirtuada por las discretas capacidades perceptivas, mnemónicas y comunicativas del ser humano ${ }^{61}$. Y eso por no hablar de la ductilidad de la voluntad humana para someterse a las querencias torcidas de los implicados en el proceso ${ }^{62}$. La realidad material es menos permeable a la manipulación ${ }^{63}$. Es tal la complejidad de los nudos de relaciones fácticas, que el número de modificaciones necesarias de la realidad resulta inasumible para el hombre ${ }^{64}$. A la postre, cualquier alteración de la realidad material deja señales y acaba por quedar en evidencia. Esta consideración se condensa agudamente en el conocido aforismo, propio del ámbito del CommonLaw, «factscannot lie» ${ }^{65}$.

vi) La seguridad también se puede abordar desde una perspectiva lógica o argumentativa. Se ha dicho que la prueba indirecta entraña un riesgo de error mucho más elevado que la prueba directa ${ }^{66}$. La prueba directa exige superar una sola etapa inferencial - la propia del examen crítico de la fiabilidad de la fuente de prueba-, mientras que la prueba indiciaria requiere indefectiblemente acometer dos etapas ${ }^{67}$. La primera, tiene por objeto el examen crítico de las fuentes de prueba de los indicios, y la segunda, atiende propiamente al paso del hecho conocido al hecho desconocido. Ciertamente, convengo en este punto con quienes han puesto sobre la mesa esta acertada observación. Sin embargo, discrepo abiertamente a la hora de extraer consecuencias epistemológicas de esta diferencia estructural que existe entre ambos métodos de prueba ${ }^{68}$. No se puede negar que cuanto mayor sea el número de pasos, superior será la posibilidad de incurrir en un error ${ }^{69}$. Pero no se trata de que en cada eslabón

61 Cfr. GianturCO, 1958: 133.

62 Cfr. J. J. GONZÁLEZ, 1975: 380.

63 Cfr. Burrill, 1868: 233; BONNIER, 1869: 356, señala que los indicios también son susceptibles de manipulación. En idéntico sentido, ELLERO, 1994: 101.

64 Al respecto, señala MuÑOZ, 1987: 254, que un haz de múltiples indicios concatenados es muy difícil de prefabricar o de que resulte de la pura casualidad.

65 Por todos, Burrill, 1868: 217; Silva, 1944: 23; Dellepiane, 1961: 94.

66 Cfr. RoCHA, 1967: 61.

67 Extremo que no admite discusión. Cfr. GORPHE, 1955: 43-44; Climent, 2005: 862 y 870; GIRONI, 2008: 123; IGARTUA, 2009b: 645. Incluso se ha defendido que serían tres los estadios que se deben superar en la prueba indirecta. FERRAJOLI, 1995: 130, los ordena del modo siguiente: $1{ }^{\circ}$ Valoración de la prueba directa que sostiene el indicio; $2^{\circ}$ Inferencia identificativa entre la proposición que resulta de la prueba del indicio y la propia del indicio; $3 .^{\circ}$ Inferencia asociativa entre el indicio y el factumprobandum.

68 M. GASCÓN, 2010a: 82, afirma que «la idea de que la prueba directa es la que menos puede conducir a error judicial hay que «ponerla en cuarentena»». Por su parte, GIRONI, 2008: 150, sostiene que más pasos no implica necesariamente debilitamiento, ni error.

${ }^{69}$ Cfr. A. Díaz, 2002: 373, y Climent, 2005: 863. 
inferencial el razonamiento vaya debilitándose y perjudicándose, hasta resultar completamente erróneo ${ }^{70}$. No puede perderse de vista que, en todo momento, aludimos a un riesgo, no a un hecho real y efectivo. Quiere decirse con ello que por más riesgo que pueda existir en el caso de la prueba indiciaria, dicha potencia no se actualizará si nos conducimos de forma rigurosa en las distintas etapas inferenciales que podamos acometer ${ }^{71}$. Por otra parte, la tesis controvertida incurre —en mi opinión- en un grave error conceptual de base. Me explico. La supuesta pérdida de valor de la cadena de inferencias por el solo hecho de transitar de un eslabón a otro no es aplicable al razonamiento propio de los hechos. Tiene plena aplicabilidad, sí, en el ámbito del cálculo probabilístico, donde la probabilidad de cada paso del conjunto contribuye a reducir la probabilidad final del resultado último. Pero lo que vale para la ciencia matemática, no sirve en absoluto para el hecho ${ }^{72}$.

Además, no me parece que podamos abandonar, ni hacer de menos, a un método probatorio simplemente porque propicia más oportunidades para incurrir en equívo$\cos ^{73}$. Para darse cuenta de la debilidad intrínseca del argumento basta con trasladar el planteamiento a otros campos del saber y del hacer, donde debería abandonarse o restringirse numerosas prácticas intelectuales y manuales por la sola razón de que encierran un mayor peligro de errar ${ }^{74}$.

Por otra parte, me resisto a aceptar tal argumento a la vista de otra consideración que se me antoja de hondo calado, no obstante pasar inadvertida de ordinario. Debemos reparar en el hecho de que, no pocas veces, las máximas de experiencia que sostienen pruebas indiciarias - en sus dos pasos o etapas lógicas- cuentan con un nivel de aceptación, en la comunidad, muy superior, por ejemplo, a los postulados de la psicología del testimonio —en especial, en lo que atiende al lenguaje no verbal- que ni son pacíficos, ni son asequibles para un lego en la materia y, lo que es peor, suelen ser desconocidos para los juzgadores — que se sirven de ordinario de sus propias máximas de experiencia vulgares-, cuyo fundamento y rigor han sido puestos en entredicho

70 Idea muy extendida que expone muy gráficamente RocHA, 1967: 61, al decir que pierden fuerza de convicción según que el hecho verificado se va alejando del juzgador, tal como pierde impulso la piedra a medida que se distancia de la mano que la arroja. Tal concepción cuenta con valedores de la talla de FERRAJOLI, 1995: 131; D. GONZÁLEZ, 2010: 313 —aunque de forma un tanto dubitativa—; y, más claramente, GuDíN, 2007: 17 .

${ }^{71}$ IGARTUA, 2009b: 646, critica la teoría de que a mayor número de eslabones, mayor debilidad del razonamiento. «[...] Todo depende, no del número, sino de la conclusividad de las reglas inferenciales empleadas». «[... Lo que finalmente cuenta es la calidad de la regla con la que se construye la inferencia». Entiendo que a esto se refiere M. GASCÓN, 2010b: 83-84, cuando dice que «podría decirse a este respecto, que, ciertamente, el valor probatorio de la prueba directa (una aserción verificada sobre el hecho que se pretende probar) es tendencialmente mayor que el de la indirecta [...]. Pero sólo «tendencialmente», pues el valor probatorio de una prueba (sea ésta directa o indirecta) no depende sólo de este dato, sino también — como es evidente- de su calidad epistemológica, es decir, de su grado de certeza. También defiende este planteamiento, SILVA, 1944: 20; LEONE, 1963: 164; ONECHA, 1971: 955; GUASCH, 1998: 301.

72 Una justificación muy sólida se encuentra en IACOVIELLO, 1997: 208, quien se apoya en las conclusiones alcanzadas en este sentido por COHEN y por EGGLESTON. En la misma línea, e igualmente provechosa, resulta la aportación de LOMBARDO, 1999: 506-508. Ya en su momento, GIANTURCO, 1958: 143-145, atacó duramente la procedencia de emplear la probabilidad matemática y sus axiomas (entre ellos, se contaría el principio de transitividad) en el juicio de hecho.

73 Cfr. Burrill, 1868: 214.

74 De rechazarse lo complejo con base en el riesgo de yerro, deberían abandonarse, por ejemplo, técnicas quirúrgicas de alta dificultad. 
con frecuencia por los expertos ${ }^{75}$. En pocas palabras, a menudo resulta más asequible inferir un hecho a partir de un cuerpo de evidencia material que concluir la fiabilidad de un testigo. Y, en consonancia, el riesgo de error es claramente superior en este último caso $^{76}$, aunque sólo se tenga que superar un nivel de inferencias, a diferencia de lo que acontece con la prueba indirecta.

vii) Hemos dejado para el final —intencionadamente- el principal de los argumentos de orden epistemológico frente a la DHPI. A mi modo de ver, toda la prueba directa es presuntiva en esencia ${ }^{77}$. Es más, la legitimación epistemológica de la prueba directa proviene de la prueba indirecta. Me explico. Si se considera probado un enunciado fáctico controvertido con base en una prueba testifical — por ejemplo—, no se debe sólo y principalmente a que tal o cual testigo haya efectuado una afirmación factual de idéntico contenido al factumprobandum, sino a que el juzgador ha concluido racionalmente que el testigo es fiable ${ }^{78}$. Pues bien, tal conclusión sobre la fiabilidad de la fuente de prueba ${ }^{79}$ no se funda, en último término, en prueba directa, diría que nunca. Siempre, acaban por aparecer indicios en el punto de arranque de la valoración crítica de las pruebas directas ${ }^{80}$.

75 Cfr. IgaRTuA, 1995: 28. En general, sobre el peligro de las máximas de experiencia y en el concreto momento de su elección, IACOVIELLO, 1995: 414.

76 Claramente J. J. GONZÁLEZ, 1975: 381 —sostiene que si elaborásemos un estudio estadístico, resultarían más errores con el empleo de prueba directa—; MIRANDA, 1997: 224 — quien defiende que la prueba directa también da lugar a errores_-; se aprecia una intuición en este sentido en VEGAS, 1993: 139, nota 139. Es más, BELLOCH, 1992: 39, ve el peligro de la prueba indirecta en los supuestos en que ésta se basa en prueba directa.

$77 \mathrm{Cfr}$., en este sentido, Burrill, 1868: 210; FrAMARINO, 1896: 188; JiMÉNEZ, 1949: 418; GORPHE, 1955: 39 - quien excluye de esta afirmación, no obstante, a la prueba directa por excelencia, el reconocimiento judicial; me permito discrepar de este parecer—; GIANTURCO, 1958: 134; DELLEPIANE, 1961: 62 —[...] Todas las pruebas llamadas directas o naturales se reducen, en último análisis, a la prueba de indicios»—; MUÑOZ, 1967: 207 — «...] La convicción descansa en todos los casos sobre presunciones»—; del mismo autor, más modernamente, 2001: 400; BRICHETTI, 1973: 121 —sostiene, incluso, que también se construyen inferencias en el reconocimiento judicial—; M. A. DíAZ, 1988: 298 — quien sólo lo intuye-; MARTínEZ, 1993: 58 y 60; ELLERO, 1994: 66 y 75; IACOVIELlO, 1995: 419 y 1997: 200; UBERTIS, 1995: 81; M. GASCÓN, 1999: 154; PAGANO, 2002 : 98; Climent, 2005: 865; GirOni, 2008: 124; SANTORIEllo, 2008: 343; ANDRÉS, 2009: 50 — «[...] «cualquier prueba es siempre indiciaria, ya que todo conocimiento probatorio es inferencial»—; IGARTUA, 2009 b: 645 — «...] En mayor o menor grado, todas las pruebas son indiciarias [...]»—; M. GASCÓN, 2010a: 99; TARUFFO, 2012: 221

78 Llega a conclusiones similares, DöHring, 1972: 16 y 66, y TARUFFO, 2012: 1102

79 ANDRÉs, 2009: 85, habla de la «fuente de información».

80 Frente a este planteamiento, se han alzado voces críticas que defienden una neta distinción entre las presunciones, por un lado, y la valoración de la prueba, por otro. Claramente, SERRA; más tímidamente, VEGAS, 1993: 143, y de forma decidida, recientemente, siguiendo al primero, ABEL, 2013: 162-163. Para el primero-SERRA, 1993: 555-, «las máximas de experiencia utilizadas en las presunciones tienen carácter específico relacionado con el caso concreto, mientras que las utilizadas en la valoración de la prueba tienen carácter genérico, con validez para cualesquiera procesos en que se utilicen los mismos medios de prueba». Frente a tal aserto, cabe objetar que toda máxima de experiencia — ya sea aplicable a aspectos fáctico-sustantivos, como a la propia valoración de la prueba- es, por definición, genérica, atendida su naturaleza de ley, regla o patrón que generaliza frecuencias fenomenológicas, a través de una inferencia inductiva cuantitativa. Por otra parte, resulta engañosa la distinción porque las máximas de experiencia que se emplean para la valoración de la prueba se podrían considerar igualmente casuísticas o concretas. Sólo se aplican a los supuestos de valoración de tal o cual prueba. Pero lo mismo acontece con las máximas de experiencia que sólo son de aplicación en los casos de simulación contractual o para la determinación del dolo de matar. Asimismo, SERRA - 1993: 555 - sustenta la pretendida diferenciación en que «[... en la valoración de la prueba el hecho afirmado instrumentalmente a través de los medios de prueba, y el derivado de la valoración judicial, son idénticos [...]». Me permito discrepar de tal afirmación. El factumprobandum (la proposición de que la concreta fuente de prueba objeto de crítica es fiable) se relaciona con una serie de hechos-base completamente distintos, merced 
Efectivamente, sobre la base de datos fácticos —indicios_ que se desprenden del medio de prueba o que resultan de otras actividades probatorias dentro del mismo proceso, se aplican máximas de experiencia y se alcanzan conclusiones sobre la confiabilidad de los medios probatorios ${ }^{81}$.

Aunque quizás le resulte obvio al lector lo que se acaba de afirmar, me resisto a dejar pasar la oportunidad de expresarlo de forma gráfica. Recuperemos a nuestro testigo Sempronio. Afirma que presenció, desde una ventana de su casa, cómo Cayo apuñalaba a Ticio. Supongamos que la dirección letrada de la acusación propone la testifical de Aulo, con el sólo propósito de proporcionar argumentos de credibilidad en relación con Sempronio. El tal Aulo, para más señas, es el compañero de piso y de estudios de nuestro testigo principal. Aulo declara en el plenario que él se encontraba en su habitación, cuando Sempronio se puso a gritar desaforadamente que estaba presenciando un homicidio. Al llegar hasta la ventana, Aulo ya no pudo ver nada, porque el crimen ya se había cometido. Así las cosas, ¿concluimos que Sempronio es fiable simplemente en atención al testimonio de Aulo? ¿o, primero que nada, se deberá concluir la fiabilidad de éste último? La respuesta se nos antoja obvia. Pero, pongamos ahora, que la credibilidad de Aulo se hace descansar en el testimonio de Luventicus, quien daría razones para creer que efectivamente Aulo se encontraba en el piso en torno a la hora de ocurrencia de los hechos. Tal cadena de testimonios - amén de que no se da en la praxis forense- - se agotará en algún momento. Y ese último eslabón sólo podrá considerarse digno de crédito merced a prueba indirecta.

Volvamos al principio. Sin desmerecer el concurso de Aulo (que podría considerarse un indicio más para inclinarnos por la confiabilidad de Sempronio), habrá que estar a otras cosas: la efectiva posibilidad de percepción de Sempronio (distancia, cantidad de luz, vista del testigo, etc.), a la correcta conservación del recuerdo (si han aparecido fotografías del sospechoso Cayo, antes de que nuestro testigo se dirigiera por vez primera a la Policía), y asî podríamos continuar enumerando factores que deben tomarse en consideración en la labor critológica de la prueba testifical.

Tan es así que se dan paradojas sumamente curiosas, como es el caso de la valoración de la declaración de la víctima en el marco del proceso penal. El propio Tribunal

al efecto asociativo que ejercen las máximas de experiencia que resulten de aplicación. Así, por ejemplo, se puede concluir que el testigo Sempronio es fiable porque se ha probado su localización en las inmediaciones del lugar de ocurrencia de los hechos, su visión es correcta, su memoria no se ha visto afectada por ningún tipo de interferencia, etc. Y la relación entre una cosa - factumprobandum - y las otras —indicios- es posible porque sólo es posible percibir correctamente un suceso si uno se encuentra próximo, porque se precisa carecer de afecciones oculares para poder visualizar adecuadamente y así podríamos seguir enunciando máximas de experiencia.

En realidad, la discrepancia es puramente terminológica, como parece dar a entender F. GASCÓN, 1999: 33, y, muy claramente, aunque se refiera al caso italiano, LOMBARDO, 1999: 436-437. Los conceptos son, en última instancia, idénticos. Lo que acontece es que no se quiere reputar presunción —a lo que sí lo es-y, en su lugar, se alude a las máximas de experiencia como si se tratara de algo diferente. A este respecto, conviene efectuar dos precisiones (insisto, puramente terminológicas). En primer lugar, entre las presunciones judiciales cabe distinguir entre presunciones de fin y presunciones de medio (como estableciera MUÑOZ, 1967: 248). Las primeras se dirigen a la prueba de un concreto factumprobandum, directa o indirectamente vinculado con el supuesto de hecho de una norma. Las segundas se emplean para acometer el examen crítico de la prueba directa, a fin de poder determinar su confiabilidad. En segundo lugar, las máximas de experiencia, por sí solas, son de todo punto inoperantes. Sin indicios, no pueden prestar ningún servicio. En realidad, los que propugnan una diferencia entre ambos términos, no niegan que el mecanismo intelectual que se emplea para determinar la confiabilidad de la prueba directa contiene los elementos propios de la presunción y, aún mejor, se desarrolla con un esquema inferencial propiamente presuntivo.

${ }_{81}$ Sobre presunciones de medio, GORPHE, 1955: 48. Para una descripción del proceso inferencial seguido a la hora de valorar la prueba directa, vid. VEGAS, 1993: 143; IACOVIELLO, 1995: 413; UBERTIS, 1995: 81; F. GASCÓN, 1999: 33; Climent, 2005: 89; M. GASCÓN, 2010a: 92. 
Supremo — al elaborar una relación de, por así decir, criterios valorativos ${ }^{82}$ — vino a establecer de forma implícita la insuficiencia de la narración del sujeto pasivo del delito para conseguir la enervación de la presunción de inocencia. Exige, a tal efecto, la concurrencia de corroboración periférica, que tendrá que ser necesariamente indiciaria ${ }^{83}$.

Si la corroboración periférica procediera de prueba directa — pongamos, por ejemplo, el caso de un testigo presencial o de una grabación audiovisual_-, la enervación de la presunción de inocencia ya no sería cosa exclusiva del testimonio de la víctima, por lo que ya no sería preciso contar con corroboración periférica alguna. El problema surge, precisamente, en aquellos supuestos en que sólo se cuenta, como prueba directa, con la declaración del sujeto pasivo del delito. Aquí es donde se revela imprescindible — según, insisto, el criterio del Tribunal Supremo- contar con prueba indiciaria que respalde la credibilidad de la sedicente víctima. Y, a poder ser, los indicios deberán revestir naturaleza física o material (rasguños o hematomas, por ejemplo, en un supuesto de violencia de género, acaecida en la intimidad de la vida familiar).

Esto no hace más que demostrar que la prueba directa hay que valorarla y que, a tal efecto, lo realmente conducente es la prueba indirecta. La primera precisa indefectiblemente del concurso de la segunda. Es más, la pretendida autosuficiencia de la prueba directa se derrumba. Está visto que no surte el capital efecto de enervar la presunción de inocencia sino se concluye su fiabilidad, a través — paradójicamente- de prueba indirecta ${ }^{84}$. Curiosamente, de esta forma se ha venido a consagrar — de forma implícita- la conveniencia de que las pruebas directa e indirecta vayan juntas, de la mano, de cara al buen fin de la probanza de los hechos ${ }^{85}$, con lo que ambos tipos se complementan y no se enfrentan.

Por consiguiente, si un elemento esencial de la prueba directa es la presunción judicial, necesariamente las supuestas deficiencias de ésta última se trasladan a la conclusión alcanzada merced a la prueba directa ${ }^{86}$. En último término, ambos métodos de prueba quedan al mismo nivel de calidad epistémica, en la medida en que uno de ellos forma parte consustancial del otro.

\subsubsection{Argumentos lógicos}

i) La DHPI peca de incongruente. Lo que, por otra parte, invita a pensar en su inconsistencia intrínseca. Me explico. Contrariamente a lo que cabría esperar, sus premisas conceptuales no desembocan en una propuesta expresa y tajante de erradicación de la prueba indiciaria de nuestro sistema procesal ${ }^{87}$. Cuanto menos, la propalada de-

82 Consúltese, por todas, STS, Sala 2. ", núm. 1029/1997, de 29 de diciembre, núm. rec. 832/1996, FFJJ 4. ${ }^{\circ}$ y $5 .^{\circ}$ (La Ley 1134/1998).

83 Cfr. FuENTES, 2000: 177 y 190-191.

84 Cfr. ibid., 176.

85 Como ya recomendara en su día Burrill, 1868: 226.

86 LOMBARDO, 1999: 476-477 y 497, afirma que «la principale conseguenza del carattere tautologico dell'inferenza è che il grado di conferma proprio della sua premessa si trasferisce automaticamente sulla sua conclusione». Parecen compartir esta perspectiva, J. J. GONZÁLEZ, 1975: 391; MARTínEZ, 1993: 57-58; FERRAJOLI, 1995 : 132 — «la probabilidad o fuerza inductiva de las pruebas afecta a la fiabilidad o crédito subjetivo de la fuente o del medio de prueba: la sinceridad, la espontaneidad, el desinterés y, más en general, la confiabilidad de los testimonios [...]»-; GIRONI, 2008: 132-133.

87 Cfr. M. GASCÓN, 1999: 154-155. 
ficiencia intrínseca de la prueba indirecta aconsejaría reducirla al campo de la justicia cautelar. En cualquier caso, su —aquí negada — minusvalía clama por su supresión —a nivel normativo y, por supuesto, en el ámbito aplicativo - como método de prueba sobre el que hacer descansar un pronunciamiento condenatorio. No se puede defender con ahínco la menor calidad epistemológica de la prueba indiciaria y, al mismo tiempo, admitir que sobre ella se puedan imponer, por ejemplo, penas privativas de libertad. Si tan insegura y peligrosa resulta, un Estado de derecho no debería poder permitirse contar con ella ${ }^{88}$.

ii) La incongruencia se agrava —en el plano de la justicia criminal—, cuando por mor de no dejar impunes muchos delitos - para los que de ordinario se carece de prueba directa-, se admite la prueba indiciaria como un mal menor. Es tanto como reconocer su deficiencia - hasta el punto de que si se cuenta con prueba directa, se huye de aquélla como de la peste-, pero, al mismo tiempo, supone conformarse con lo que poco que se tiene, por malo que sea ${ }^{89}$. Y lo que es mucho peor. Se consiente que nuestro sistema jurídico penal albergue dos clases de condenas, cuyo juicio de hecho difiere en la tipología de prueba empleada con su diferente calidad epistemológica. En algunos casos, la condena se alcanza sobre la base de prueba óptima en un sentido epistémico, mientras que otros supuestos, al mismo resultado condenatorio se llega a partir de prueba de discreto valor epistemológico. Esta diversidad de grados de calidad que se predica de ambas dos pruebas acarrea unas consecuencias penológicas inaceptables ${ }^{90}$.

iii) La consustancial vinculación demostrada entre prueba directa e indirecta nos conduciría — de ser consecuentes con la DHPI- a un resultado aterrador. Si desterráramos la prueba indiciara del catálogo de métodos de prueba, deberíamos admitir que la prueba directa se quedaría automáticamente huérfana del imprescindible sostén crítico que legitima su aceptación en un determinado supuesto. Si la prueba directa es presuntiva en esencia, necesariamente nos hemos de ver privados del instrumento epistémico que nos permite determinar la confiabilidad de la primera. Por consiguiente, una de dos. O aceptamos cualquier medio de prueba que se proponga en juicio, o rechazamos también la prueba directa. En cualquiera de los dos casos, las consecuencias son funestas para el sistema judicial. Una toma de postura coherente con la DHPI supone torpedear al Estado de derecho en su misma línea de flotación. ¿Acaso nos imaginamos explicando a los justiciables que se les ha condenado en un determinado caso sobre prueba directa cuyo control de calidad — de fiabilidad— se ha realizado empleando un instrumento pernicioso y de escaso —o nulo-valor epistémico? Evidentemente, dichos justiciables se cuestionarían — con razón— la legitimidad del propio sistema de justicia.

iv) La máxima «praesumptiopraesumptionis non admitittur» encierra, también, una grave inconsistencia, si se la considera detenidamente. Sólo se puede probar los indicios mediante prueba directa, pero ésta última siempre tiene indicios en su base, de modo que nunca se podrá probar la fiabilidad de la directa con la que se lleva a término la probanza de los propios indicios. Sin duda, un círculo vicioso. Y lo que queda,

88 Como ha sostenido coherentemente Gudín, 2007: 13 y 17.

${ }^{89}$ Según IgARTUA, 2009b: 643, significaría resignarse a una calidad de conocimiento de inferior condición.

90 Cfr. Miranda, 1997: 221. 
en definitiva, es la imposibilidad real de utilizar la prueba indirecta ${ }^{91}$, para la que no quedaría otro destino posible que su destierro lógico.

La aludida máxima supone un contrasentido también desde otra perspectiva. La prueba indirecta no sirve para probar un indicio y, sin embargo, sí reviste eficacia para la probanza de los hechos base de un delito y acabar condenando por ello ${ }^{92}$. Si quien puede lo más, puede lo menos, la máxima de constante mención debe desaparecer definitivamente de nuestra cultura jurídica y judicial ${ }^{93}$.

\subsubsection{Argumento bistórico}

La concepción negativa de la prueba indirecta se explica, además de por las razones ya vistas, como consecuencia de una inercia histórica, que conviene clarificar, muy brevemente ${ }^{94}$ :

i) Si bien es cierto que la distinción entre pruebas directa - representativa o inartificial— e indirecta — crítica o artificial— se remonta a ARISTÓTELES, la discriminación peyorativa es obra de los juristas del derecho intermedio, que se dejaron seducir por la idea de que la primera está exenta de actividad racional y, por consiguiente, de los peligros de la lógica y la retórica ${ }^{95}$.

ii) Sobre la base de esta equívoca concepción, y especialmente en el ámbito penal, la prueba reina en la Edad Media fue la directa y, más que ninguna, la confesión del reo. La prueba indirecta —insisto, sinónimo de indiciaria — se empleaba como un mero instrumento que propiciaba la consecución de aquélla primera, al operar como condición para poder aplicar el tormento al sospechoso ${ }^{96}$, del que se esperaba obtener precisamente la confesión del delito. Una vez proscrita la tortura, los indicios perdieron, en gran medida, su sentido, contemplándose solamente para la imposición de penas menores, quedando ostensiblemente devaluado su papel en el juicio de hecho ${ }^{97}$.

iii) La escasa fiabilidad de la prueba indirecta para los juristas tardomedievales —que ha prosperado con éxito hasta nuestros días - precipitó en una visión vulgar o capitidisminuida de la indicios, a los que tradicionalmente se ha asociado el carácter de combustible de un razonamiento provisional (de ahí que su utilidad se haya confinado al ámbito de decisiones «provisionales»: medidas cautelares, etc.) ${ }^{98}$.

91 Cfr. IgARTUA, 2009a: 503.

92 Denuncia esta incongruencia de forma harto clara, BELLOCH, 1992: 45. La constatación de este sinsentido invita a ponerse en guardia frente a interpretaciones literales del art. 386 LEC — como la que efectúa A. DíAZ, 2002: 374-375—, de las que se extrae una supuesta voluntad del legislador de confirmar la máxima praesumptiopraesumptionis non admitittur. En este sentido sigo la interpretación contraria, propuesta por MiRANDA, 2000: 519.

93 Cfr. J. J. González, 1975: 390; Guasch, 1998: 301; M. Gascón, 1999: 154; Climent, 2005: 923.

94 Para un análisis en profundidad de la cuestión, vid. Rosoni, 1995. Asimismo, resulta sumamente ilustrativo el compendio de derecho histórico que se contiene en la STSJ de Madrid, núm. 13/2004, de 5 de mayo, núm. rec. 1/2004, FJ 7. ${ }^{\circ}$ (La Ley 14148/2004).

95 Sobre este extremo, vid., por extenso, Rosoni, 1995: 52-55

96 Sobre el particular, resulta sumamente ilustrativo DE HEviA, 1825: 237-241. Para un análisis histórico detallado, vid. GORPHE, 1955: 40.

97 Cfr. SERRA, 1969: 701 .

98 Cfr. Igartua, 2009b: 642. 
Sin que sea posible extenderse aquí y ahora sobre el particular, conviene, no obstante, dejar apuntadas algunas reflexiones que permitirán comprender el embrollo histórico en el que se ha convertido la prueba indirecta.

La concepción vulgar de presunción es en realidad una inferencia presuntiva que no ha superado el tamiz de la contradicción y, por tanto, el necesario enfrentamiento con otras hipótesis competidoras. Es plausible, sí, pero no basta para condenar, aunque efectivamente resulta suficiente para imponer medidas cautelares personales, por ejemplo. En el ámbito penal, para que una hipótesis presuntiva prospere - - y, si se trata, del último eslabón, permita enervar la presunción de inocencia- debe ser consistente, per se, y, además, excluir indirectamente a cualquier hipótesis alternativa aducida por la defensa ${ }^{99}$.

Un sencillo ejemplo facilitará la adecuada comprensión de lo dicho. Supongamos que Ticio es sorprendido saliendo de la vivienda de Cayo por una ventana trasera, a altas horas de la noche, portando un cuchillo en la mano, con sangre del segundo por todas partes (en sus manos, en su ropa y hasta en su rostro). Para colmo de males, era de público conocimiento la mala relación existente entre ambos.

De primeras, los indicios expuestos (y otros más que se podrían añadir) permiten construir un conjunto de inferencias presuntivas cuya conclusión última es que - prima facieTicio mató a Cayo. Y sobre esta inferencia podría asentarse la adopción de una medida cautelar sobre la persona de Ticio.

Pero con estos mimbres no podría tejerse una condena. Y ello porque si bien es plausible el razonamiento expuesto, también la defensa podría construir la siguiente hipótesis alternativa acerca de lo sucedido: Ticio acudió a Cayo para arreglar definitivamente sus diferencias, encontrándose a éste último tendido en el suelo, con el cuchillo clavado en el abdomen, agonizando. Ticio extrajo el arma del cuerpo de Cayo, sin poder hacer nada para evitar su muerte, pese a los denodados intentos por frenar la hemorragia. Al escuchar ruido en la calle, Ticio — a quien todos tenían por enemigo acérrimo de Cayo- se asustó y decidió marcharse, de forma discreta, portando el cuchillo en el que había estampado sus huellas, para evitar que lo relacionaran con el crimen. Lógicamente, estaba manchado de sangre por todas partes (como consecuencia de su vano intento de frenar la pérdida de sangre de la víctima).

Pues bien, en el juicio plenario, se acabó contando con sólo estos indicios. Llegado el momento del fallo, el juzgador no podría sino absolver a Ticio, toda vez que la masa indiciaria obrante en la causa abona la construcción de dos inferencias presuntivas igualmente plausibles, lo que debe desembocar en la absolución de Ticio.

Pues bien, la prueba indirecta a la que nos hemos venido refiriendo en este estudio no se debe identificar con la inferencia prima facie —o presunción vulgar-, sino con el razonamiento que ha superado el análisis crítico judicial con más (aunque no siempre se dé) el enfrentamiento a otras hipótesis competidoras ${ }^{100}$.

iv) Además, el carácter vulgar de presunción —el que prosperó en épocas tardomedievales-, que se asimila generalmente a la idea de «sospecha», se fundaba en algo que hoy es impensable, como es el hecho de exonerar a los indicios de la obligación de su prueba ${ }^{101}$.

99 Parece aludir a esto mismo CLiment, 2005: 861, cuando define la presunción vulgar como aquella que no se ha practicado o frente a la que no se ha podido practicar prueba en contrario.

100 Así lo vislumbró con meridiana claridad SERRA, tal y como refiere CLIMENT, 2005: 861-862.

101 Cfr. CaRnelli, 1971: 59 . 
De todo cuanto se acaba de exponer sucintamente, se desprende que la noción de prueba indirecta, que ha recibido el respaldo del Tribunal Constitucional y el Tribunal Supremo, no es en absoluto la que puede denominarse vulgar, sino la que se ha venido en denominar técnica o propiamente jurídica. A fin de cuentas, la prueba indirecta que pretendemos equiparar a la prueba directa no es la inferencia presuntiva prima facie o lógicamente incompleta, sino la que ha superado los controles de calidad epistemológica y, eventualmente, las hipótesis competidoras o alternativas. Así pues, en gran medida las deficiencias que se achacan a la prueba indirecta son, en realidad, características de la inferencia presuntiva prima facie, no de la presunción técnica o jurídica. Con ello, se desarbola otra de las razones para recelar de la prueba indiciaria.

\subsection{Exposición de la DEPPDI}

Se debe partir de la admisión, sin remilgos, ni temores, de la diferencia intrínseca, sustancial, que existe entre ambos métodos de prueba. Al menos, en cuanto al procedimiento lógico que permite alcanzar la convicción sobre el factumprobandum ${ }^{102}$. Tal y como se ha señalado al comienzo, en el caso de la prueba directa nos encontramos ante un razonamiento puramente identificativo. Por el contrario, cuando se trata de prueba indirecta el iter lógico es esencialmente asociativo. El indicio y el factumprobandum constituyen proposiciones factuales completamente diferentes, que, pese a ello, guardan una relación epistemológica o conceptual (con independencia de que en determinados casos dicha conexión sea también de orden material).

Desde una óptica estrictamente epistémica, resulta perfectamente posible alcanzar la convicción sobre la justificación de un determinado enunciado fáctico por ambas vías $^{103}$. La epistemología no ha contradicho tal cosa hasta la fecha. Y es natural a la vista de la propia experiencia humana. Tan válidos pueden resultar, para adquirir conocimiento, un testigo como una huella ${ }^{104}$. Basta en cada caso con que se sigan escrupulosamente los métodos comprobados de validación de los propios instrumentos de transmisión del conocimiento. Así pues, habida cuenta que se predica la misma eficacia de ambas, y, por consiguiente, se les asigna el mismo rango, no resulta posible, por tanto, establecer una jerarquía en cuanto a su valencia probatoria ${ }^{105}$.

Por otra parte, la concurrencia de un nivel de riesgo superior en el empleo - en algunos casos, no siempre ${ }^{106}$ - de la prueba indirecta en relación con la directa no se traduce — como ya hemos visto — en una automática e inevitable falencia de la primera. El riesgo se conjura sencillamente con un discurrir riguroso en cada una de las etapas o fases del iter lógico que se tengan que superar. Y superado tal riesgo, es decir, evitada la actualización de la mera potencia, la conclusión alcanzada merece toda la confianza en un estricto sentido epistémico. En suma, un mayor riesgo de

102 Cfr. Framarino, 1896: 192-193; Garraud, 1921: 785; Dellepiane, 1961: 63; Belloch, 1992: 42-43; LOMBARDO, 1999: 488 y 498-499.

103 Cfr. FASSONE, 1995: 321; SANTORIELLO, 2008: 338.

104 Cfr. Santoriello, 2008: 349.

105 Cfr. GIRONI, 2008: 149.

106 Cuando el indicio se sustenta en prueba personal (y pienso que también en prueba documental), GORPHE, 1955: 460; DELlePiANE, 1961: 59. 
equívoco, per se, no degrada el método o procedimiento seguido. Y nunca puede hacerse bandera de algo que puede ser, pero que no es necesariamente, para establecer discriminaciones.

Superado el principal escollo que encuentra la equiparación entre ambos métodos de prueba, se llega al punto relevante de esta doctrina. Me refiero a la inevitable compenetración que existe entre ambas ${ }^{107}$. No sólo no son mutuamente excluyentes, sino que se aprecia la existencia de una recíproca interdependencia ${ }^{108}$, que se manifiesta del modo siguiente:

a) La prueba directa es indirecta, en su base, en la medida en que la solidez de la primera depende del juicio de fiabilidad a la que tiene que ser sometida por el juzgador, que, como se ha afirmado anteriormente, es de naturaleza presuntiva. No en vano, ya hemos puesto de manifiesto hasta qué punto es así en el supuesto paradigmático de la declaración de la víctima, en el proceso penal.

b) La prueba indirecta, aunque se pueda sustentar en una cadena de presunciones, acaba, siempre, por hallar su último fundamento en prueba directa ${ }^{109}$.

El razonamiento siempre tiene que tener en su origen un dato, cuya obtención no se logra con una inferencia, sino, que resulta, bien de la propia contemplación de la realidad, bien de la comunicación por una persona o de la proyección de un instrumento. No puede darse una cadena infinita de inferencias porque, tarde o temprano, la elucubración racional tendrá que nutrirse de la realidad material.

Esto último comporta que no sea posible predicar una menor valencia probatoria de la prueba indirecta. Dicho de otra forma, no se puede establecer una discriminación peyorativa ex ante. Sino, únicamente ex post ${ }^{110}$. Veámoslo detenidamente. Para ello, partamos de la premisa de que la prueba directa es indiciaria en su base. Sentado esto, añadamos otra consideración no menos importante. La calidad de la prueba indirecta resulta de la calidad de los indicios en los que se funda, de la máxima de experiencia empleada y, en fin, de la inferencia como un todo. Pues bien, si la prueba directa es indiciaria, en el sentido antes indicado, la calidad de la prueba directa vendrá dada por la calidad de los indicios, de la máxima de experiencia y de la inferencia, como conjunto, con los que se ha construido el juicio de fiabilidad de la primera ${ }^{111}$. Por tanto, enfrentadas de inicio dos pruebas, una directa y otra indirecta, no será posible conferir a una de ellas mayor valencia probatoria que a la otra. Se tendrá que examinar la calidad de los elementos componentes de los procesos inferenciales que entrañan ambas. Ex post, sí cabrá extraer una conclusión, inclinándose el fiel de la balanza por una o por otra, por méritos lógicos propios, y no como consecuencia de prejuicios, que como hemos visto responden, entre otras cosas, a una malentendida herencia histórica ${ }^{112}$.

107 Cfr. GORPHE, 1955: 43.

108 Cfr. BurRILl, 1868: 231; FramarinO, 1896: 195 — quien tiene dicho que «[...] no hay prueba directa sin mezcla de indirecta»-; GARRAUd, 1921: 786; Dellepiane, 1961: 63; BRICHETTI, 1973: 125; ELLERO, 1994 : 89; DELGADO, 1996: 391 —habla de «entrecruce» entre una y otra clase de prueba-.

109 Cfr. ElLERO, 1994: 89.

110 Cfr. Iacoviello, 1997: 176-177; S. E. Rodríguez, 2013: 309-310.

111 Así dice FERNÁNDEZ, 2005: 257-258, que «[...] el procedimiento judicial para valorar la prueba indiciaria viene a coincidir básicamente con el procedimiento para valorar la prueba directa $[. ..] \gg$.

112 Sobre esta cuestión, vid. CONIGLIO y COMOGLIO, ambos citados por LOMBARDO, 1999: 501. 


\subsection{Toma de postura}

De cuanto se lleva dicho, creo haber justificado argumentalmente la que es mi postura definitiva en relación con la controversia entre las pruebas directa e indirecta y que se concreta en la plena y absoluta equiparación entre ambas. Considero que existen razones suficientes para defender la absoluta y definitiva abrogación de la DHPI. Y con ello, entiendo que existe una base sólida para combatir abiertamente todas las consecuencias procesales que hemos predicado de la DHPI.

\section{CONCLUSIONES}

Del conflicto inexistente entre prueba directa y prueba indirecta que se ha desarrollado en el presente estudio se deducen las siguientes tres conclusiones:

Primera. La doctrina de la hipovaluación de la prueba indirecta debe ser abandonada de forma absoluta y definitiva, toda vez que la aquejan una serie de deficiencias de diverso orden (legal, epistemológico, lógico e histórico) que la invalidan por completo.

Segunda. La anterior debe dejar paso a la doctrina de la completa equiparación entre los métodos probatorios directo e indirecto, a la vista de la idéntica valencia probatoria de ambos.

Tercera. No sólo no existe un verdadero conflicto entre pruebas directa e indirecta, ni una suerte de diferencia jerárquica entre ambas, sino que son totalmente interdependientes. Y ello hasta tal extremo de que la prueba directa, sin el apoyo de la indirecta, queda vacía de contenido, sucediendo lo mismo a la inversa. Por ello, debería propiciarse, desde luego por el Legislador, y también por los órganos jurisdiccionales, el empleo conjunto de ambos métodos probatorios, siempre que sea posible.

\section{BIBLIOGRAFÍA}

ABEL, X., 2013: «Configuración de las reglas de la sana crítica en la Ley 1/2000, de Enjuiciamiento Civil», Revista Vasca de Derecho Procesal y Arbitraje, 25 (2): 135-166.

Amodio, E., 1977: «Motivazione della sentenza penale», Enciclopedia del Diritto (XXVII: Morale-Negozio), Milano: Giuffrè, 181-257.

ANDRÉS, P., 1992: «Acerca de la motivación de los hechos en la sentencia penal», Doxa, 12: 257-300.

- 2009: Prueba y convicción judicial en el proceso penal, Buenos Aires: Hammurabi.

AsEncIO, J. M., 1989: Prueba probibida y prueba preconstituida, Madrid: Trivium.

BELlOCH, J. A., 1992: «La prueba indiciaria», La sentencia penal (Manuales de formación continuada: 13), Madrid: Consejo General del Poder Judicial, 29-93.

Bentham, J., 2001: Tratado de las Pruebas Judiciales, trad. de M. Ossorio, Granada: Comares.

BONNIER, M. E., 1869: Tratado teórico-práctico de las pruebas en derecho civil y penal (II), trad. de J. Vicente y CaRAVANTES, Madrid: Revista de Legislación.

BRICHetTi, G., 1973: La «evidencia» en el derecho procesal penal, trad. de S. SENTís, Buenos Aires: Ediciones Jurídicas Europa-América.

BurRiLL, A. M., 1868: Treatise on the nature, principles and rules of circumstantial evidence, especially that of presumptive kind in criminal cases, New York: Baker, Voorhis \& Co. Law- 
Publishers (disponible únicamente en formato electrónico, en http://archive.org/stream/ atreatiseonnatu00burrgoog\#page/n12/mode/2up; fecha de consulta: 23 de abril de 2013).

CABAÑAS, J. C., 1992: La valoración de las pruebas y su control en el proceso civil. Estudio dogmático y jurisprudencial, Madrid: Trivium.

CARNELli, L., 1971: «Sobre la presunción (Homenaje)», Revista de Derecho Procesal Iberoamericana, 1: 45-63.

CHOCRÓN, A. M., 2004: Las presunciones como método de prueba en el proceso laboral. Especial referencia a la «presunción de duración indefinida del contrato de trabajo», Murcia: Laborum.

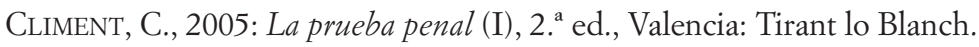

De Hevia, J., 1825: Curia Filípica (I), Madrid.

De Miranda, C., 2014: «La prueba indiciaria: ¿Deducción? ¿Inducción? ¿Abducción? ¿O inferencia a la mejor explicación?», en J. A. GARCía AMADO y P. R. BONORINO (coord.), Prueba y razonamiento probatorio en Derecho. Debates sobre abducción, Granada: Comares, 189-230.

Delgado, J., 1996: «Prueba de indicios», en J. Delgado (dir.), La prueba en el proceso penal (Cuadernos de Derecho Judicial: 9), Madrid: Consejo General del Poder Judicial, 375-423.

Dellepiane, A., 1961: Nueva teoría de la prueba, 6. ${ }^{\text {a }}$ ed., Bogotá: Temis.

DíAz, A., 2002: La prueba en la nueva Ley de Enjuiciamiento Civil. Tratamiento y práctica, Barcelona: Bosch.

DíAz, M. A., 1988: Tratado sobre las pruebas penales, 2. ${ }^{a}$ ed., México: Porrúa.

DíAz-REgañón, C., 1996: El régimen de la prueba en la responsabilidad civil médica. Hechos y Derecho, Cizur Menor (Navarra): Aranzadi.

DöHRING, E., 1972: La prueba. Su práctica y apreciación (La investigación del Estado de los hechos en el proceso), trad. de T. A. BANZHAF, Buenos Aires: Ediciones Jurídicas Europa-América.

ELLERO, P., 1994: De la certidumbre en los juicios criminales o tratado de la prueba en materia penal, trad. de A. POSADA, Buenos Aires: Librería El Foro.

FASSONE, E., 1995: «La valutazione della prova nel processo penale: dogmatismi antichi e consapevolezze nuove», en M. BESSONE y R. GuASTINI (eds.), La regola del caso. Materialisulragionamentogiuridico, Padova: Cedam, 317-336.

FERnÁNDEZ, M., 2005: Prueba y presunción de inocencia, Madrid: Iustel.

FerRAJOlI, L., 1995: Derecho y razón. Teoría del garantismo penal, trad. de P. ANDRÉs, A. RuIZ, J. C. Bayón, J. Terradillos y R. Cantarero, Madrid: Trotta.

FERRER, J., 2006: «La valoración de la prueba: verdad de los enunciados probatorios y justificación de la decisión», Estudios sobre la prueba, México: Universidad Nacional Autónoma de México, 1-45.

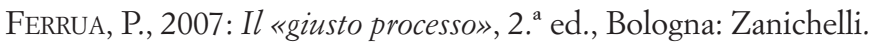

Framarino, N., 1896: Lógica de las pruebas en materia criminal (I), Madrid: La España Moderna.

FueNTES, O., 2000: «La valoración de la prueba indiciaria y la declaración de la víctima en los delitos sexuales», Problemas actuales de la administración de justicia en los delitos sexuales, Lima: Defensoría del Pueblo, 151-247.

GARBERÍ, J., 2004: La prueba civil. Doctrina, jurisprudencia y formularios sobre prueba, procedimiento probatorio y medios de prueba en la nueva Ley de Enjuiciamiento Civil, Valencia: Tirant lo Blanch.

Garraud, R., 1921: Précis de Droit Criminel, 13. a ed., Paris: Librairie de la Société du Recuil Sirey.

GASCÓN, F., 1999: El control de la fiabilidad probatoria: «prueba sobre la prueba» en el proceso penal, Valencia: Revista General del Derecho. 
GASCÓN, M., 1999: Los hechos en el derecho. Bases argumentales de la prueba, Madrid: Marcial Pons.

- 2010a: «La motivación de la prueba», El Derecho en acción. Ensayos sobre interpretación y aplicación del Derecho, Lima: Ara, 79-105.

- 2010b: Los hechos en el derecho. Bases argumentales de la prueba, 3. ${ }^{\text {a }}$ ed., Madrid: Marcial Pons.

GianturCO, V., 1958: La prova indiziaria, Milano: Giuffrè.

GimÉNEZ, J., 2006: «La prueba indiciaria en el proceso penal», Jueces para la Democracia, 56: 75-86.

GIRONI, E., 2008: «La prova indiziaria», en A. GAITO, La prova penale (III), Torino: Utet Giuridica, $115-165$.

González Bustamante, J. J., 1975: Principios de Derecho Procesal Penal Mexicano, 6. a ed., México: Porrúa.

GONZÁLEZ LAGIER, D., 2003: «Hechos y argumentos (Racionalidad, epistemología y prueba de los hechos en el proceso penal) (II)», Jueces para la democracia, 47: 35-51.

- 2006: «Argumentación y prueba judicial», Estudios sobre la Prueba, México: Universidad Nacional Autónoma de México, 89-134.

- 2010: «Hechos y argumentos. Racionalidad epistemológica y prueba de los hechos en el proceso penal», en P. R. BONORINO (ed.), El Derecho en acción. Ensayos sobre interpretación y aplicación del Derecho, Lima: Ara, 269-341.

GoRPHE, F., 1955: De la apreciación de las pruebas, Buenos Aires: Ediciones Jurídicas EuropaAmérica.

GUASCH, S., 1998: El hecho y el derecho en la casación civil, Barcelona: J. M. Bosch.

GudíN, F., 2007: «Aplicación de la lógica como ciencia en el proceso penal: análisis de la prueba indiciaria», Revista de Derecho Penal, 22: 11-41.

IACOVIELLO, F. M., 1995: «I criteri di valutazione della prova», en M. BESSONE y R. GUASTINI (eds.), La regola del caso. Materiali sul ragionamento giuridico, Padova: Cedam, 391-426.

- 1997: La motivazione della sentenza penale e il suo controllo in cassazione, Milano: Giuffrè.

IGARTUA, J., 1993: «Una interpretación funcional de la "libre valoración” de las pruebas penales», Jueces para la Democracia, 18: 44-52.

- 1995: Valoración de la prueba, motivación y control en el proceso penal, Valencia: Tirant lo Blanch.

- 2009a: «Los indicios tomados en serio», Razonamiento e interpretación jurídica, Lima: Ara, 477-509.

— 2009b: «Dónde reside la ambigüedad de los indicios en tanto que elementos de prueba?», en J. HeRnÁndez GarCía (dir.), 99 cuestiones básicas sobre la prueba en el proceso penal, Manuales de Formación continuada del Consejo General del Poder Judicial, Madrid: CGPJ, 637-646.

JimÉNEZ, E., 1949: Derecho procesal penal (1), Madrid: Revista de Derecho Privado.

LeguisAmón, H. E., 2006: Las presunciones judiciales y los indicios, 2. ${ }^{a}$ ed., Buenos Aires: Rubinzal-Culzoni.

Leone, G., 1963: Tratado de Derecho Procesal Penal (II), trad. de S. SEnTís, Buenos Aires: Ediciones Jurídicas Europa-América.

Lombardo, L., 1999: La prova giudiziale. Contributo alla teoria del giudizio di fatto nel processo, Milano: Giuffrè.

Manzanares, J. L., 1992: «Sobre la presunción de inocencia» (I), Actualidad Penal, 12: 93-103. MARTíneZ, A., 1993: «La prueba indiciaria», La prueba en el proceso penal, Madrid: Centro de Estudios Judiciales. Ministerio de Justicia, 53-73. 
MirANDA, M., 1997: La minima actividad probatoria en el proceso penal, Barcelona: J. M. Bosch.

- 2000: «Las presunciones», en AlONSO-CuEVILlas, Instituciones del nuevo proceso civil. Comentarios sistemáticos a la Ley 1/2000 (II), Barcelona: Difusión jurídica y temas de actualidad.

MitTermaier, C. J. A., 1929: Tratado de la prueba en materia criminal, 8. a ed., Madrid: Reus.

MuÑOZ, Ll., 1967: Técnica Probatoria. Estudio sobre las dificultades de la prueba en el proceso, Barcelona: Praxis.

- 1987: «Agatha Christie y la prueba de presunciones», Estudios de Práctica Procesal, Barcelona: Bosch, 254-255.

- 2001: Fundamentos de Prueba Judicial Civil: LEC 1/2000, Barcelona: J. M. Bosch.

- 2007: Introducción a la probática, Barcelona: Bosch.

- 2009: Curso de Probática Judicial, Madrid: La Ley.

- 2012: Curso superior de probática judicial, Madrid: La Ley.

Nieva, J., 2010: La valoración de la prueba, Madrid: Marcial Pons.

Onecha, C., 1971: «Las presunciones judiciales», Revista de Derecho Procesal Iberoamericana, 4: 949-958.

Pagano, F. M., 2002: Principios del Código Penal, trad. de Zaffaroni, Buenos Aires: Hammurabi.

PASTOR, F., 2003: Prueba de indicios, credibilidad del acusado y presunción de inocencia, Valencia: Tirant lo Blanch.

Prieto-Castro, L., y Gutiérrez de Cabiedes, E., 1982: Derecho Procesal Penal, 2. ${ }^{a}$ ed., Madrid: Tecnos.

RifÁ, J. M., 2000: «Presunciones judiciales», en M. A. Fernández Ballesteros, J. M. RifÁ y J. F. VALLS, Comentarios a la nueva Ley de Enjuiciamiento Civil (II), Barcelona: Iurgium, $1782-1786$.

RIVERA, R., 2011: La prueba: un análisis racional y práctico, Madrid: Marcial Pons.

RochA, A., 1967: De la prueba en Derecho (I), 5. a ed., Bogotá: Lerner.

RODRíGUEZ, J., 2012: «¿Destruye la presunción de inocencia una prueba de cargo menos segura cuando era posible una prueba de cargo directa más segura?», Diario La Ley, 7788.

RodrígueZ, S. E., 2013: «Prueba directa y prueba indiciaria», en OrTEgA GARCíA, Teoría del Derecho y Argumentación Jurídica. Ensayos contemporáneos, Valencia: Tirant lo Blanch, 287312.

Romero, A. M., 1986: La prueba procesal penal y su valoración psicológica, Madrid: Colex.

RosONI, I., 1995: Quae singula non prosunt collecta iuvant. La teoria della prova indiziaria nell'età medievale e moderna, Milano: Giuffrè.

RuIZ, E., 1995: «Indicios, presunciones y motivación de las sentencias», Estudios de Derecho procesal penal, Granada: Comares.

SANGUinetTI, L., 1979: La valutazione della prova penale, Milano: Giuffrè.

SANTORIELlO, C., 2008: «I criteri di valutazione della prova (fra massime d'esperienza, regole di giudizio e standards d'esclusione)», en A. GAITO, La prova penale (III), Torino: Utet Giuridica, 325-411.

SeOAne, J. L., 2007: La prueba en la Ley de Enjuiciamiento Civil 1/2000, 2. ${ }^{\text {a }}$ ed., Cizur Menor (Navarra): Thomson-Aranzadi.

SERRA, M., 1969: «Función del indicio en el proceso penal», Estudios de Derecho Procesal, Barcelona: Ariel, 699-711.

- 1993: «De las presunciones», en M. Albaladejo, Comentarios al Código Civil, 2. ${ }^{a}$ ed., Madrid: Ministerio de Justicia, Secretaría General Técnica, XVI: 543-588. 
SiLVA, V., 1944: Presunciones e indicios en el proceso penal, Madrid: Instituto Editorial Reus.

TARufFo, M., 2008: La prueba, trad. de L. ManríqueZ y J. Ferrer, Madrid: Marcial Pons.

- 2012: La prova nel processo civile, Milano: Giuffrè.

TOMÁs y VALIENTE, F., 1987: «In dubio pro reo, libre apreciación de la prueba y presunción de inocencia», Revista Española de Derecho Constitucional, 209: 9-34.

Tonini, P., 2003: Manuale di procedura penale, 5. ${ }^{a}$ ed., Milano: Giuffrè.

Ubertis, G., 1995: La prova penale. Profili giuridici ed epistemologici, Torino: Utet.

Vegas, J., 1993: Presunción de inocencia y prueba en el proceso penal, Madrid: La Ley.

VVAA, 2006: Principios de Derecho Global. 1.000 Reglas, principios y aforismos comentados, 9. ${ }^{a}$ ed., Cizur Menor (Navarra): Aranzadi, marginal 902. 